\title{
LA CREACIÓN DE LOS MUSEOS ECLESIÁSTICOS DE GALICIA
}

\author{
Por \\ NURIA SERRANO TÉLLEZ
}

El trabajo de investigación para determinar el origen de los museos eclesiásticos gallegos ha sido arduo y complicado. En general, se desprende de este estudio una dicotomía entre los proyectos, colecciones y museos que existieron y la documentación encontrada —inexistente en la mayoría de los casos-.

Los archivos consultados para desarrollar este tema han sido tres: el Archivo Histórico Diocesano, el Archivo Catedralicio y el Archivo del Convento de San Francisco, todos en la ciudad de Santiago de Compostela.

La nota característica de esta búsqueda ha sido la ausencia prácticamente total de documentación relativa a aquellos museos o colecciones eclesiásticas de los que teníamos vagas noticias. Únicamente se han encontrado informaciones colaterales a nuestro tema de escasa trascendencia para nuestro trabajo.

Ante el vacío documental la opción era tomar como punto de partida de este estudio las valiosísimas guías y monografías de Galicia y de la ciudad de Santiago de Compostela de finales del siglo XIX y primera mitad del XX.

Las guías, eran por lo general obras escritas para turistas o peregrinos y siempre mencionan la existencia de museos y colecciones visitables.

"CUADERNOS DE ESTUdIOS GALLEGOS", Tomo XLIV, Fascículo 109, Santiago 1997. 


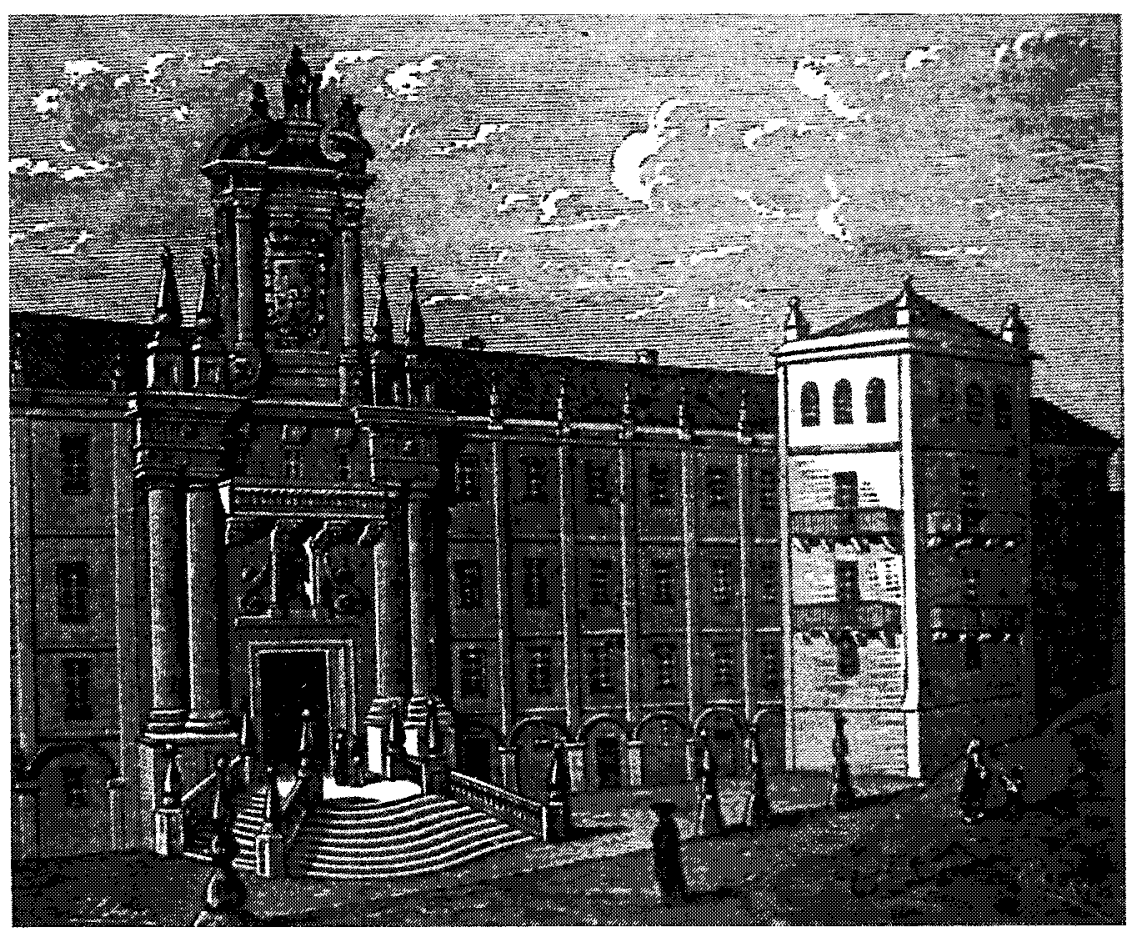

San Martín Pinario pudo haber sido la sede del primer museo eclesiástico de Galicia, segundo de la ciudad de Santiago de Compostela.

Las monografías, referidas a la ciudad de Santiago de Compostela pretendían mostrar una imagen de la ciudad desde el punto de vista de su historia, de su arte y de las curiosidades que ésta ofrecía, entre ellas los museos y colecciones.

Entre las fuentes bibliográficas consultadas, publicaciones periódicas y revistas, destaca por su importancia para nuestro estudio la revista Galicia Diplomática, que supone un continuo foro de debate abierto sobre la conveniencia de dotar a la ciudad de Santiago de Museos, tanto civiles como eclesiásticos, y que supone una fuente de información inigualable para nuestro tema.

Por el contrario, la inexplicable ausencia de noticias relativas a $\mathrm{Mu}-$ seos y colecciones en publicaciones eclesiásticas como el Boletín Oficial de la Diócesis de Santiago, es un dato a tener en cuenta: ninguna publicación de este tipo recoge noticias o datos de proyectos de realización de museos o de colecciones ya existentes.

"CUADERNOS DE ESTUDIOS GALLEGOS", Tomo XLIV, Fascículo 109, Santiago 1997. 
Este estudio parte pues, de la contradicción de elementos muy diversos que denotan la escasa atención que dichas colecciones o museos despertaron en su momento en los lugares en que se originaron.

\section{LA GÉNESIS DE LOS MUSEOS ECLESIÁSTICOS DE SAN- TIAGO DE COMPOSTELA}

En la Génesis de los museos eclesiásticos de Galicia, al igual que en la génesis del primer museo de arqueología civil gallego', ocupa un papel determinante la actividad desarrollada por dos personalidades de la cultura en Galicia de finales del siglo XIX: José Villaamil y Castro y Bernardo Barreiro de Vázquez Varela. Como elemento de referencia importante una asociación: la Sociedad Económica de Amigos del País de Santiago.

José Villaamil y Castro realizará una encomiable labor en pro de la formación de museos de antigüedades en Galicia, junto a su amigo Bernardo Barreiro de Vázquez Varela que promocionará el tema del coleccionismo y de los museos desde la revista de su propiedad, de la que era también director, Galicia Diplomática.

Si llama poderosamente la atención el apoyo incondicional ante la constitución de un Museo Diocesano por parte de José Villaamil y Castro y Bernardo Barreiro de V.V., hay un hecho que nos sorprende sobremanera: la ausencia de opiniones, apoyo o posible ejercitación de influencia de uno de los eruditos y más prestigiosos canónigos de la Catedral compostelana de la época, Antonio López Ferreiro.

En efecto, si bien López Ferreiro participó en las mismas fechas en la comisión de estudio de la constitución del Museo Arqueológico Central de la Sociedad Económica - de la que era socio-, nunca se pronunció, escribió o actuó en favor de la constitución de un Museo de Arqueología Sagrada en Galicia.

Era evidente, que López Ferreiro dominaba a la perfección dicha materia, de la que era titular desde 1887 en la Cátedra del mismo nombre del Seminario de San Martín Pinario. Prueba de ello es la publicación en

\footnotetext{
${ }^{1}$ Nos referimos al hoy desaparecido Museo Arqueológico Central de la Sociedad Económica de Amigos del País de Santiago, en el edificio de San Clemente, inaugurado en julio del año 1884 .
}

"CUADERNOS DE ESTUdIOS GALLEGOS", Tomo XLIV, Fascículo 109, Santiago 1997. 
1889 de un libro que se adoptó como texto de enseñanza en todos los Seminarios de España: Lecciones de Arqueología Sagrada.

Aunque sabemos que apenas ejerció como profesor de dicha asignatura, no deja de sorprendernos que, en su amplia bibliografía nunca hayamos encontrado ninguna mención relativa a la idea de promocionar un proyecto de este tipo en Galicia. Las causas de esta actitud son difíciles de aventurar y por tanto no dejan de ser un misterio.

Por el contrario, su discípulo y sustituto en la docencia, Eladio Oviedo y Arce dedicará unos párrafos importantes a la idea del establecimiento de museos diocesanos como apoyos imprescindibles para ejercer la enseñanza de la asignatura de Arqueología Sagrada en los Seminarios, llegando a mencionar la inminente apertura de un museo de estas características en la Archidiócesis de Santiago como veremos más adelante.

Junto a Villaamil, Barreiro y las actividades de la Sociedad Económica de Amigos del País a la que ambos pertenecían - la más destacada en el tema que nos ocupa, la creación del Museo Arqueológico Central de Galicia-, un acontecimiento singular va a ser el detonante para llamar la atención definitivamente sobre la necesidad de constituir museos en las Diócesis que salvaguarden el gran patrimonio eclesiástico.

Nos referimos a la celebración en el año 1889 del Congreso Católico Nacional de Madrid, que se saldará con la publicación de una interesante Memoria sobre los Museos diocesanos y sobre juntas periciales consultivas respecto a Arquitectura, Antigüedades y Bellas Artes Sagradas.

En este Congreso jugará un papel importante José Villaamil y Castro con una decisiva aportación personal en pro de la constitución de este tipo de museos.

Junto a estas circunstancias, hemos de tener en cuenta que, la implantación de la asignatura de Arqueología Sagrada en el Seminario Central de Santiago, como elemento fundamental en la formación de los futuros sacerdotes de cara a la salvaguarda del patrimonio eclesiástico, va a ser el primer paso para el proyecto de lo que hubiera sido el primer museo gallego de la Iglesia: el Museo del Seminario Central o de San Martín Pinario.

José Villaamil y Castro (Madrid, 12.11.1838 - id., 27.9.1910).

Archivero, bibliotecario, anticuario e historiador por la Escuela Superior de Diplomática de Madrid y doctor en Derecho. Realizó una impor- 
tante labor profesional y escribió un sinfín de monografías y artículos en las revistas Museo Español de Antigüedades, El Arte en España, Semanario Pintoresco Español, El Museo Universal, La Ilustración Gallega y Asturiana, Galicia Diplomática, Galicia Histórica... Fue socio de mérito de la Sociedad de Amigos del País de Santiago. Destacó además por ser coleccionista de antiguiedades, siendo su colección la base del primer museo ar-

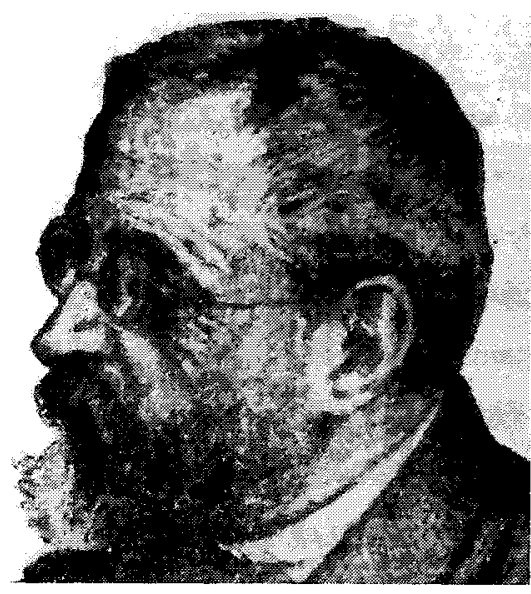
queológico de Galicia, hoy desaparecido: el Museo Central de Galicia de la Real Sociedad Económica de Amigos del País de Santiago.

Bernardo Barreiro de Vázquez Varela (Santiago, 20.1.1850 - Coruña 1904).

Archivero del Ayuntamiento de Santiago en 1881 y posteriormente de la Diputación de La Coruña. Fue insigne historiador e investigador, fundador y propietario de la revista Galicia Diplomática y uno de los eruditos de mayor producción en la segunda mitad del siglo XIX en Galicia. Destacó por su actuación decisiva en la constitución del Museo Arqueológico Central de la Sociedad Económica junto a Villaamil y Castro.

Antonio López Ferreiro (Santiago, 9.11.1987 - Vedra 20.2.1910)

Canónigo de la Catedral de Santiago, historiador, arqueólogo y novelista. Tras finalizar sus estudios en Santiago se matricula en la Escuela Superior de Diplomática de Madrid, donde inicia sus primeras publicaciones históricas, consiguiendo en 1865 el título de archivero bibliotecario. En 1871 recibe

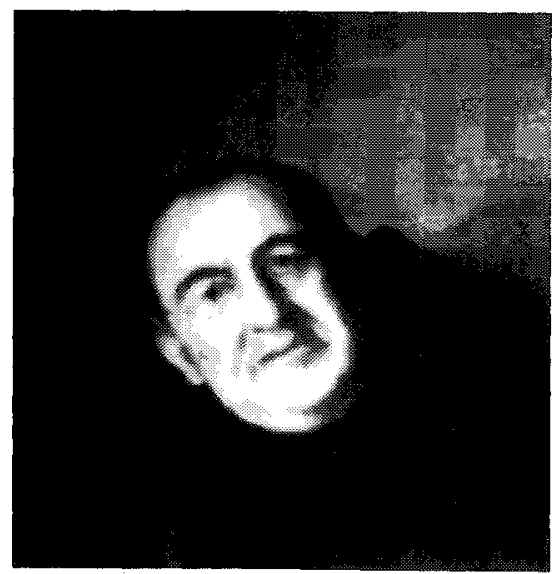

"CUADERNOS DE ESTUDIOS GALLEGOS", Tomo XLIV, Fascículo 109, Santiago 1997. 
el cargo de canónigo del cabildo metropolitano y participa activamente en las comisiones de estudio de las reformas de la catedral. Publicó multitud de artículos en periódicos y revistas de la época así como numerosas monografías. En total, 105 títulos entre libros, folletos, artículos y traducciones. Los estudios publicados en la revista Galicia Histórica y sobre todo, los once tomos de su Historia de la Santa A.M. Iglesia de Santiago de Compostela, fueron decisivos para considerarle uno de los más prestigiosos historiadores que nunca tuvo Galicia.

La Sociedad Económica de Amigos del Paìs (Santiago, 1783).

Por iniciativa del canónico de la catedral, Antonio Páramo y Somoza y diversas personalidades compostelanas, se presentó en diciembre de 1783 el proyecto de constitución de una Sociedad Económica de Amigos del País en Santiago. Abrió sus puertas en febrero del año siguiente. Tras varias etapas de resurgimiento e inactividad se restablece definitivamente la Sociedad en 1834 y hasta nuestros días. En sus estatutos figuraban los fines a cumplir: «mejorar la industria popular y los oficios, auxiliar su enseñanza, divulgar los secretos de las artes, anunciar las máquinas que simplifiquen las maniobras, facilitar su ejecución y uso, fomentar la pesca..., la agricultura y cría de ganados...». Entre sus realizaciones figura la constitución del primer Museo Arqueológico de Galicia, inaugurado en el año 1884, que tras diversos avatares desapareció lamentablemente dejando un gran vacío en la historia de la museología gallega.

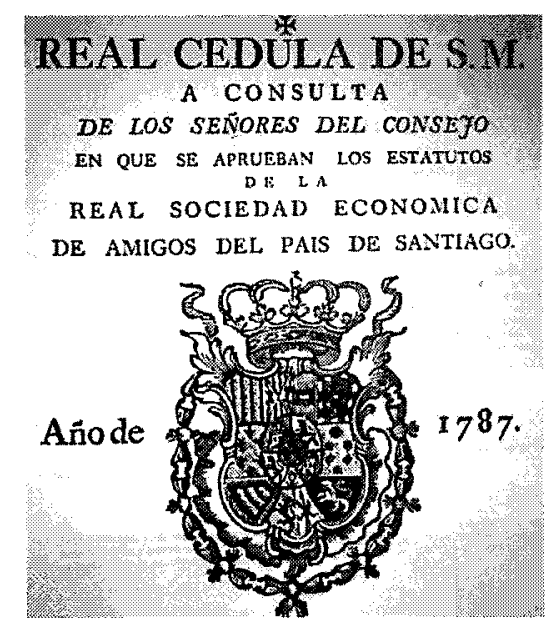

"CUAdERNOS DE ESTUdiOS GAllegOS", Tomo XLIV, Fascículo 109, Santiago 1997. 


\section{LA REVISTA GALICIA DIPLOMÁTICA Y EL PRIMER MUSEO ECLESIÁSTICO DE LA DIÓCESIS DE SANTIAGO}

En Diciembre de 1883, se anuncia en la revista Galicia Diplomática la próxima apertura de un Museo de Antigüedades en el Seminario Central, que «será uno de los mejores de España, especialmente en objetos del culto cristiano de los pasados siglos». Este Museo dependiente del Seminario Central de Santiago, proyecto del Cardenal Arzobispo de la Diócesis Payá y Rico con el concurso de gran número de profesores, se ubicaría en la sede del mismo: el Monasterio de San Martín Pinario ${ }^{2}$.

La importancia de este acontecimiento era enorme: éste hubiera sido el segundo museo en crearse en Santiago de Compostela y en toda Galicia -después del Museo Arqueológico de la Sociedad de Amigos del País de Santiago-, el primer museo eclesiástico gallego y además, el primero de España perteneciente a un seminario.

En su planteamiento inicial y desde la revista Galicia Diplomática, se establecieron algunas consideraciones relativas a lo que este museo debería ser y significar. En primer lugar, debería ser un museo que «se limitara a ciertos objetos antiguos del culto católico para el auxilio de un breve curso de arqueología sagrada».

Uno de los principales objetivos del museo, hubiera sido pues, el ilustrar a los futuros sacerdotes con nociones de arte, como complemento para un curso de arqueología sagrada. Esta formación permitiría una mejor conservación del patrimonio artístico eclesiástico de las parroquias rurales gallegas.

Se planteaba que al menos fuera el párroco una persona ilustrada para evitar el deterioro del patrimonio rural: la destrucción de altares, cornisas, ventanas o pórticos de las iglesias románicas, entre otros, era un hecho constatado, además de los numerosos robos en iglesias debido a la ausencia de medidas de seguridad.

Otro de los objetivos que se pretendían alcanzar con la creación de este museo era, «la reunión, conservación y custodia de las antiguedades arrinconadas en las sacristías y templos de tan extensa diócesis, cuadros, imágenes, esculturas, cruceros, bronces, muebles antiguos, ropas y ornamentos curiosos, libros misales y foyas de mérito, y en fin, toda clase

2 «Miscelánea», Galicia Diplomática, II, 21, Santiago, 1883, p. 164.

"CUADERNOS DE ESTUdios GALLEGOS", Tomo XLIV, Fascículo 109, Santiago 1997. 
de objeto con que se relacione un hecho histórico, leyenda o tradición religiosa importante en el país» ${ }^{3}$.

A raíz de este anuncio de apertura de un museo de la Diócesis en el Seminario Conciliar de Santiago de Compostela, comienzan a llegar a la redacción de la revista Galicia Diplomática muestras de adhesión al proyecto de fundación de museos diocesanos, justificando la necesidad de un Museo eclesiástico en Santiago como imperante.

Para algunos, debía ser un Museo, no sólo de arte cristiano, sino que admitiera el concurso y los elementos que podrían ofrecerle la Sociedad Económica de Amigos del País y la Universidad de Santiago con el pequeño depósito de antigüedades y objetos de arte que atesoraba. Para otros, debía reducirse estrictamente a su ámbito y no contar con la aportación de otras instituciones que pretendían desarrollar empresas similares, como la propia Sociedad Económica y su proyecto de Museo Arqueológico Central de Galicia, que sería inaugurado un año más tarde.

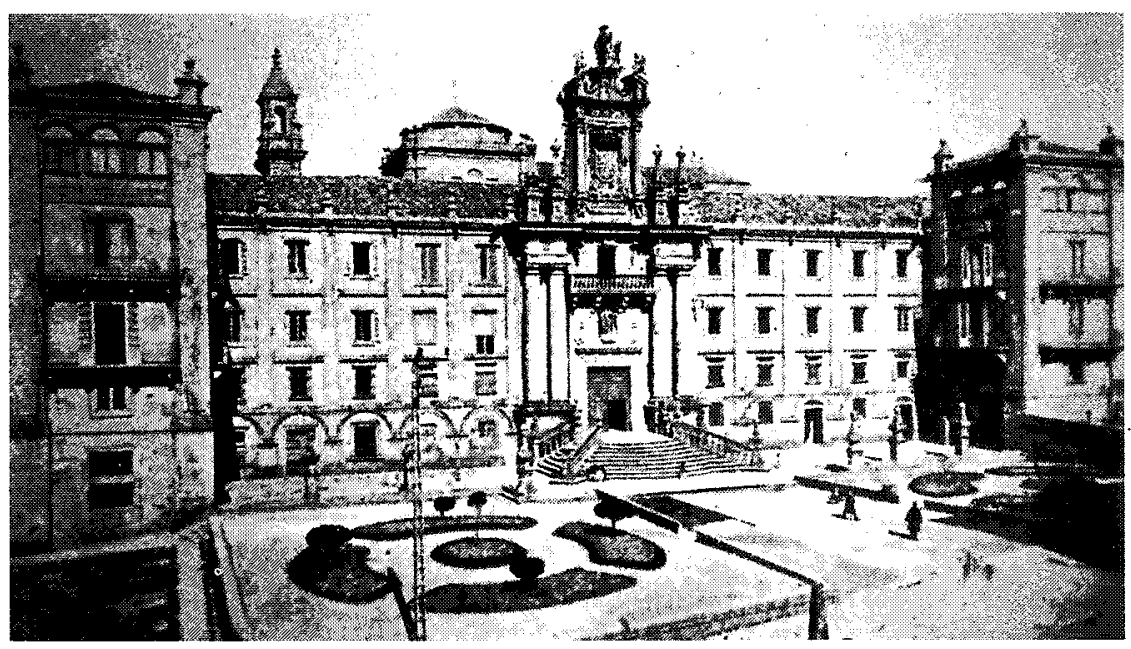

San Martín Pinario, residencia actual del Seminario Conciliar Central.

${ }^{3}$ «Los Museos de antiguedades en Santiago», Galicia Diplomática, II, núm. 22, Santiago, 1883, pp. 165-166.

"CUADERNOS DE ESTUDIOS GALLEGOS", Tomo XLIV, Fascículo 109, Santiago 1997. 
Esta corriente de opinión pudo influir en la creación de la cátedra de Arqueología Sagrada en el Seminario Central en 1887, al frente de la cual estaba el canónigo Antonio López Ferreiro. Ésta aún no existía cuando se plantea la cuestión en Compostela, de crear un Museo Diocesano. Los museos de este tipo eran considerados por aquel entonces como un recurso importante, un apoyo fundamental para la enseñanza práctica de dicha asignatura.

La enseñanza práctica, en la segunda mitad del siglo XIX, tuvo su plasmación concreta en la creación de importantes gabinetes y museos científicos en la ciudad de Santiago en la Universidad, Instituto de Segunda Enseñanza, Seminario Conciliar y Colegio Misional de San Francisco. De entre todos los gabinetes que se crearon, destacaron por la riqueza de sus colecciones los de Historia Natural, Anatomía y Física. Los gabinetes o museos artísticos no existían: tan sólo se reunían algunas colecciones o antigüedades en algunos de los gabinetes científicos como meras curiosidades. En este contexto, la aparición de un Museo de Arqueología Sagrada, es decir de arte, que sirviera de apoyo a la enseñanza de dicha asignatura, resultaba un hecho novedoso ${ }^{4}$.

Durante el año 1884, se comienzan a reunir objetos diversos de la Diócesis para iniciar los fondos del Museo y se lanzan numerosas misivas justificando el proyecto desde la revista anteriormente citada. Uno de los argumentos esgrimidos era la conveniencia de crear museos de este tipo por la recomendación expresa de los sumos Pontífices, y especialmente por León XIII. En efecto, el coleccionismo de los Papas había sido a lo largo de los siglos manifiesto y origen de la formación de Museos de primer orden y así lo argumentaban desde Galicia Diplomática:

\footnotetext{
${ }^{4}$ La enseñanza de la asignatura de arqueología y el desempeño de cargos especiales como los de Bibliotecas y Archivos de las Iglesias, se ven favorecidos en toda España a partir del año 1888 por medio del Real Decreto de 6 de diciembre de 1888 — publicado en la Gaceta de Madrid el 10 de diciembre del mismo año-. En él se establece lo siguiente: 1. La mitad de las Canongías y los Beneficios de gracia correspondientes a cada Iglesia, Catedral o Colegial será en adelante de Oposición. 2. A las Canongías o a los Beneficios que se provean por Oposición a tenor de lo determinado en el artículo precedente, podrán imponerse cargos especiales, como los de enseñar en los Seminarios, cuidar de las Bibliotecas y Archivos de las Iglesias, promover el estudio y la observancia de la Sagrada Liturgia y dirigir las Sagradas Ceremonias.
} 
«Comenzó el ejemplo en Roma por Benedicto XIV que reunió en una sala especial del Vaticano varios sarcófagos y otros restos de la antigüedad cristiana, y esta fundación tan deseada por los sabios de aquella época fue tan alabada, que el protestante Hagenbach exclamó que nada podía imaginar mejor arreglado. El caballero Pietro Vittori, célebre colector de restos del antíguo arte cristiano, hizo donación de sus colecciones al Pontífice y éstas fueron colocadas en dicho Museo. Pío VII lo tenía en grande estimación y adquirió para él la colección del abogado Mariotti. Gregorio XVI lo dotó magníficamente de una espléndida colección de pinturas en madera, de los siglos XIII, XIV y XV. Pío IX lo acredentó considerablemente y habiendo establecido el famoso Museo Cristiano del Laterano tan admirablemente arreglado por Rossi, puso en él todas las esculturas e inscripciones de las Catacumbas que entonces había en el Vaticano. Allí se ven valiosas colecciones de cuadros de las antiguas escuelas bizantina e italiana, objetos de varias especies de barro cocido, de cristal, de bronce, de plata y oro, con un gran número de piedras preciosas ¡Cuántas curiosidades de este género no podríamos reunir en España si, a imitación de Roma fundásemos Museos diocesanos! $\aleph^{5}$

Los artículos sobre museos en la revista se suceden a lo largo de los años siguientes. Eran un fiel reflejo de la necesidad que se comenzaba a sentir en toda España de conservación de las antigüedades en instituciones creadas para tal fin denominadas museos. Además, eran ya numerosos los museos provinciales que existían en ese momento y era evidente la promoción de estas instituciones que contaban ya con la elaboración de una normativa específica.

\section{EL CONGRESO CATÓLICO NACIONAL DE MADRID EN 1889 Y SU INCIDENCIA EN LA CREACIÓN DE MUSEOS ECLE- SIÁSTICOS DIOCESANOS EN GALICIA}

En el año 1889 tuvo lugar una importante reunión, el Congreso Católico de Madrid, que supuso el primer paso en la toma de conciencia entre Ios católicos y eclesiásticos de toda España de la necesidad de preservar

5 «Los Museos de la Diócesis», Galicia Diplomática, II, 30, Santiago, 1884, p. 247.

"CUADERNOS DE ESTUdIOS GALLEGOS", Tomo XLIV, Fascículo 109, Santiago 1997. 
el patrimonio de la Iglesia para la posteridad y de crear museos que albergaran los numerosos objetos dispersos por parroquias, seminarios, etc.

Para la celebración de este Congreso se determinaron diversas Secciones. La sección quinta, que llevaba por título Asuntos de Literatura, Bellas Artes y de la Prensa, planteó una serie de puntos de estudio a desarrollar, entre los que estaban los siguientes relacionados con el tema que nos ocupa ${ }^{6}$ :

«4. Importancia suma del Arte Cristiano y su poderosa influencia en las costumbres y utilidad de crear en todos los Seminarios Conciliares una Cátedra de Arqueología como ya habían hecho otros Prelados.

5. Medios para restaurar las pinturas, imágenes y demás objetos de culto, conforme a las reglas litúrgicas y a los modelos ejecutados bajo la inspiración cristiana.

6. ¿Qué estilo arquitectónico es más conveniente para los edificios religiosos? Conveniencia de crear en la capital de cada diócesis, bajo la dirección del respectivo Ordinario, un Museo de Arte Cristiano y una Junta Pericial de carácter consultivo.»

A su vez dicha sección nombró diferentes comisiones para la cual fueron designados eminentes especialistas. En la sección arqueológica se encontraba una de las personas que más influencia había tenido en la constitución del primer museo de Santiago de Compostela: José Villaamil y Castro $^{7}$.

\footnotetext{
${ }^{6}$ «Programa de los puntos sometidos al estudio del Congreso Católico y de las tesis para los trabajos», Bol. Oficial de la Diócesis de Santiago de Galicia, XXVIII, Imp. del Seminario Conciliar Central, Santiago, 1889, p. 42.

7 Además fueron designados para formar parte de esta comisión algunas personas que habían presentado al Congreso trabajos relacionados con los puntos de estudio de la misma: Juan Catalina - profesor de Arqueología en la Escuela de Diplomática de Madrid-y Enrique María Repullés - arquitecto erudito-. Se unieron a la comisión también, Liborio Acosta de la Torre - canónigo de la Catedral de Madrid--, P. Lecanda del Oratorio de San Felipe de Alcalá de Henares y Bernardino Martín Mínguez.
}

"CUADERNOS DE ESTUdIOS GALLEGOS", Tomo XLIV, Fascículo 109, Santiago 1997. 


\section{LAS CONCLUSIONES DE LA SECCIÓN QUINTA DEL CON- GRESO CATÓLICO NACIONAL: PUBLICACIÓN DE LAMEMO- RIA SOBRE MUSEOS DIOCESANOS Y SOBRE JUNTAS PERICIALES CONSULTIVAS RESPECTO A ARQUITECTURA, ANTIGÜEDADES Y BELLAS ARTES SAGRADAS}

El Congreso Católico publicó sus conclusiones en esta memoria donde se recogieron las ideas fundamentales debatidas que fueron redactadas por Liborio Acosta de la Torre, y de la que fueron ponentes José Villaamil y Castro y Juan Catalina García — ambos del cuerpo de Bibliotecarios, Archiveros y Anticuarios-y el arquitecto del Ministerio de Fomento Enrique María Repullés y Vargas ${ }^{8}$.

A raíz de la celebración del Congreso, desde la revista Galicia Diplomática y ante las cuestiones planteadas por la Sección quinta relativas a la conveniencia de crear museos de arte cristiano en la diócesis, se proponen diversas cuestiones entre las que destaca la creación de museos arqueológicos diocesanos. Se consideraba que éstos constituirían un poderoso elemento de ilustración del clero y de la cultura popular que fomentaría la afición a los estudios e investigaciones histórico-artísticas y avivaría el sentimiento del arte en todas las clases sociales...

Además, reunirían aquellos objetos innecesarios para el culto esparcidos por iglesias, catedrales, colegiales, parroquiales y monásticas con el mero esfuerzo de su traslado desde sus lugares de origen y como accesorio y complemento de los seminarios centrales. La propuesta incluso contemplaba la salvaguarda del patrimonio documental y bibliográfico de las iglesias.

La idea nos parece interesantísima, pues aún hoy día en Santiago, cien años después de esta primera propuesta — que de haberse llevado a cabo entonces habría significado la salvaguarda de un ingente patrimonio perdido en la actualidad - se plantea la cuestión de la definitiva realización de un Museo Diocesano.

\footnotetext{
${ }^{8}$ L. Acosta de la Torre, Memoria sobre el estilo más conveniente para los edificios religiosos, sobre Museos Diocesanos y sobre Juntas Periciales Consultivas respecto a Arquitectura, Antigüedades y Bellas Artes Sagradas, Tip. de los Huérfanos, Madrid, 1889.
}

"CUADERnOS DE ESTUdiOS GALlegOS", Tomo XLIV, Fascículo 109, Santiago 1997. 
Como veremos más adelante, el Museo del Seminario Central, no pasó de ser una buena idea que por motivos que desconocemos no se llegó a realizar.

Además del establecimiento de estos museos, se crearía en cada Diócesis una junta central compuesta por eclesiásticos y seglares, profesores... para la protección del patrimonio arquitectónico y mueble que interviniesen:

1. En la enajenación de objetos inútiles para el culto a fin de evitar que se enajenaran entre éstos aquellos de valor histórico-artístico.

2. En la restauración de las obras de arte que hubiesen de conservarse, como garantía de que no se encomendasen a personas no capacitadas.

3. En la adquisición de nuevos objetos artísticos para las iglesias que armonizasen con el estilo original del templo.

Cuatro elementos se consideraron fundamentales para llevar a cabo estos Museos en las Diócesis:

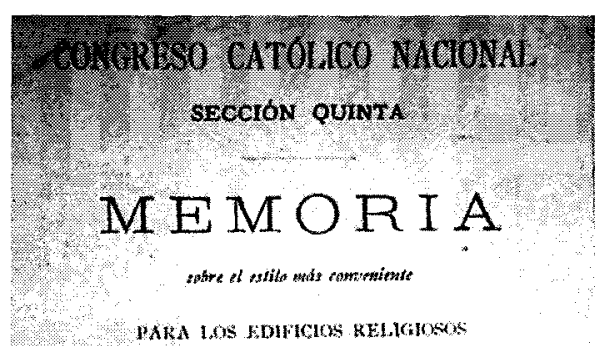

SOBRE MUSEOS DIOCESANOS

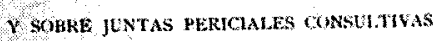

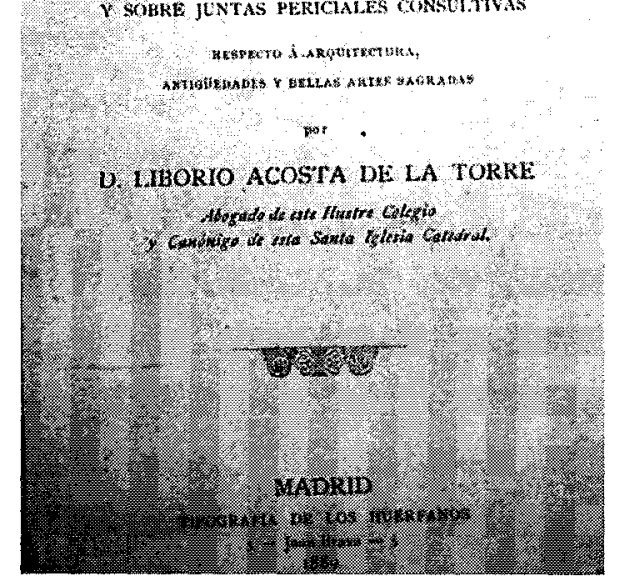

1. Una Junta ejecutiva de personas peritas.

2. Un Local a propósito para los objetos.

3. Personal que los conserve y custodie.

4. Medios para ello.

Las Juntas de cada Diócesis, revisarían y completarían los inventarios de ropas, alhajas, muebles, utensilios de culto... de iglesias, parroquias y conventos y los depositarían en los archivos episcopales. Además, cada Junta indicaría a su obispo correspondiente aquellos objetos del inventa- 
rio que deberían figurar expresamente en el Museo de su Diócesis. También sería misión de la Junta reunir objetos mediante una circular dirigida a prioras, abadesas, párrocos, rectores... y a los que coleccionan cosas antiguas, «que hoy son muchos», solicitando donativos o depósitos para contribuir a la creación de cada museo. Una vez reunidos éstos en el establecimiento, los ordenarían por secciones y por grupos y formarían un catálogo razonado descriptivo de todo cuanto el museo reuniese.

En cuanto al local necesario para la instación de museos diocesanos, sólo se le exige que «reuna las oportunas condiciones de luz, aire y desahogo, y que se dote de los enseres precisos».

El personal lo constituirían sacerdotes ilustrados y los medios necesarios no serían demasiado costosos: servicio, material de oficinas y correspondencia... que precisarían de una cantidad anual no demasiado grande.

El estimulante ejemplo de otros Museos Diocesanos como el de Vich - cuyo Obispo asistió a la Sesión de la Sección $5^{a}$ en el Congreso-y la constatación del ingente patrimonio eclesiástico amenazado, fue sin duda uno de los argumentos fundamentales presentado en las conclusiones de ese Congreso para determinar la urgente necesidad de constituir museos de este tipo.

\section{LOS ESTUDIOS DE ARQUEOLOGÍA SAGRADA Y LOS MUSEOS}

Junto a la conservación del patrimonio eclesiástico mediante la creación de Museos, destaca sobremanera el interés por formar a los futuros sacerdotes en la disciplina de la Arqueología Sagrada. A este respecto, Compostela debió de significar en el Congreso del año 1889 un magnífico modelo a imitar por el resto de las Diócesis y Seminarios: desde hacía unos pocos años contaba ya con una prestigiosa Cátedra de Arqueología en los Seminarios y con un movimiento en pro de la constitución de un Museo en proceso de definición.

Como ya hemos apuntado anteriormente, la implantación de la asignatura de Arqueología Sagrada en el Seminario Central de Santiago, como elemento fundamental en la formación de los futuros sacerdotes de cara a la salvaguarda del Patrimonio eclesiástico, hubiera sido un importante antecedente y el primer paso para el proyecto de lo que hubiera sido el primer museo gallego de la Iglesia: el Museo del Seminario Central o de San Martín Pinario.

"CUADERNOS DE ESTUDIOS GALLEGOS", Tomo XLIV, Fascículo 109, Santiago 1997. 
El estudio de Arqueología Sagrada es el comienzo de un camino de sensibilización y toma de conciencia del gran patrimonio de la Iglesia, de la necesidad de su estudio y conservación. Pero, ¿cuál era el objeto de estos estudios de Arqueología Sagrada? Eladio Oviedo Arce, profesor de la asignatura en el Seminario de Santiago por aquel entonces, expresa de la siguiente manera el objeto de la misma:

«No es la Arqueología Sagrada el mero conocimiento de las antigüedades cristianas; sino el de la antigüedad, quiere decirse, del pasado de la Iglesia Católica, por medio de los viejos monumentos o antigüedades artísticas de cualquier género... Todos los monumentos figurados por las artes, cuando menos, caen bajo el dominio de esta ciencia; los de arquitectura, escultura, glíptica, toréutica, pintura, grabado, orfebrería, herrería, cerámica, vidriería, indumentaria; así como igualmente los monumentos epigráficos, numismáticos, heráldicos, paleográficos, diplomáticos y esfragísticos; que también esos son, en su forma exterior, producto de las artes del dibujo.» ${ }^{9}$

El siglo XIX había sido el siglo de oro para la arqueología profana y sagrada: se cultivaron todas las ramas de la ciencia arqueológica, se crearon otras nuevas y se organizaron Museos y Academias Científicas. Las Academias y Sociedades históricas, geográficas, artísticas, arqueológicas y excursionistas, las publicaciones periódicas emanadas de ellos junto a la formación y reunión de colecciones y Museos de Arqueología, contribuyeron definitivamente al desarrollo de la Ciencia.

A principios del siglo XX se consideraban los siguientes museos arqueológicos como los de mayor celebridad: «...el Británico de Londres, el del Louvre y el de Cluny en París; los de Berlín, Munich y Dresde en Alemania; los de Florencia, Turín, Nápoles y Roma en Italia (en Roma, el del Vaticano, el Lateranense, el Capitolino y el Kircheriano); el Nacional y el de Pinturas del Prado en Madrid; el Nacional de Méjico; el de Gizeh en Egipto, con otros muchos de las naciones civilizadas» ${ }^{10}$.

${ }^{9}$ E. Oviedo y Arce, Seminario Conciliar Central Compostelano. Discurso inaugural del Curso Académico de 1891 a 1892, Imp. y Enc. del Seminario, 1891, pp. 14-15.

${ }^{10} \mathrm{~F}$. Naval, Elementos de Arqueología y Bellas Artes para uso de Universidades y Seminarios, Imp. y Enc. de José Saenz, Santo Domingo de la Calzada, 1904.

"CUADERNOS DE ESTUDiOS GALLEGOS", Tomo XLIV, Fascículo 109, Santiago 1997. 
De todo lo apuntado podemos pues, determinar cuales hubieran sido por tanto los fondos del Museo Diocesano de Arqueología Sagrada de Santiago: un museo donde se recogieran todo tipo de manifestaciones artísticas, epigráficas, y arqueológicas de la Diócesis.

Pero, ¿cuál fue la causa que determinó la no realización de este proyecto? Lo cierto es, que no contamos con noticias al respecto. La desaparición de la Revista Galicia Diplomática fue para nuestro estudio una grave pérdida pues a partir de entonces no tenemos ninguna noticia al respecto.

La última referencia cronológica encontrada de este museo, no es de esta revista, sino de Eladio Oviedo Arce, profesor de Arqueología Sagrada del Seminario de Santiago, que en su Discurso inaugural del Curso Académico de 1891 a 1892 hace una referencia a la institución de Cátedras y Museos de Arqueología Sagrada:

«Cátedras hay, en efecto, de esta asignatura en este Gran seminario, y en los de Mondoñedo, Oviedo, Pamplona, Tarragona, Vich, Barcelona, Sevilla, Toledo y Astorga. Esta última ciudad tiene un excelente Museo Diocesano, y otro acaba de inaugurarse en Vich. Además podemos adelantar la noticia de que en Lugo se creará muy en breve una cátedra de Arqueología Sagrada, y en esta Archidiócesis un Museo.»" ${ }^{11}$

Esta es la última confirmación que hemos encontrado de la real existencia de un proyecto, al menos hasta el año 1891, de Museo en la Archidiócesis de Santiago.

Las omisiones de López Ferreiro, del Boletín Oficial de la Diócesis, de la Documentación de los archivos consultados y el hecho de que, en el Seminario nunca hubo noticias de un museo creado en el siglo XIX, nos confirmaron definitivamente su inexistencia.

No obstante, algunas guías y monografías de la ciudad de Santiago nos crearon gran confusión: citan un Museo en el Seminario. Sobre este punto insistiremos más adelante.

Podemos concluir, que realmente hubo un proyecto de realización de Museo Diocesano en Santiago de Compostela, al menos hasta el año 1891, y que éste no se llevó a término por circunstancias que desgraciadamente no podremos llegar a conocer.

" Op. cit. pp. 58-59.

"CUADERNOS DE ESTUdIOS GALLEGOS", Tomo XLIV, Fascículo 109, Santiago 1997. 


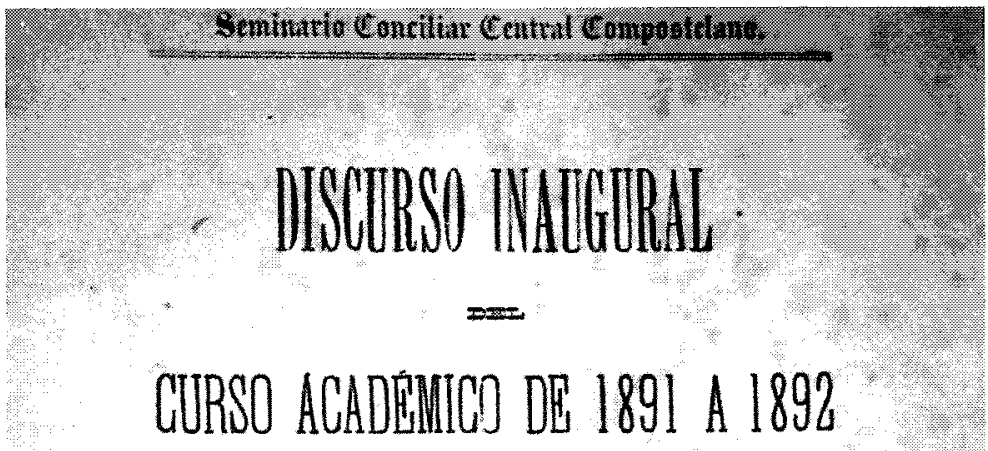

por al nocror

D. ELADIO OVIEDO ARCE, PBRO,

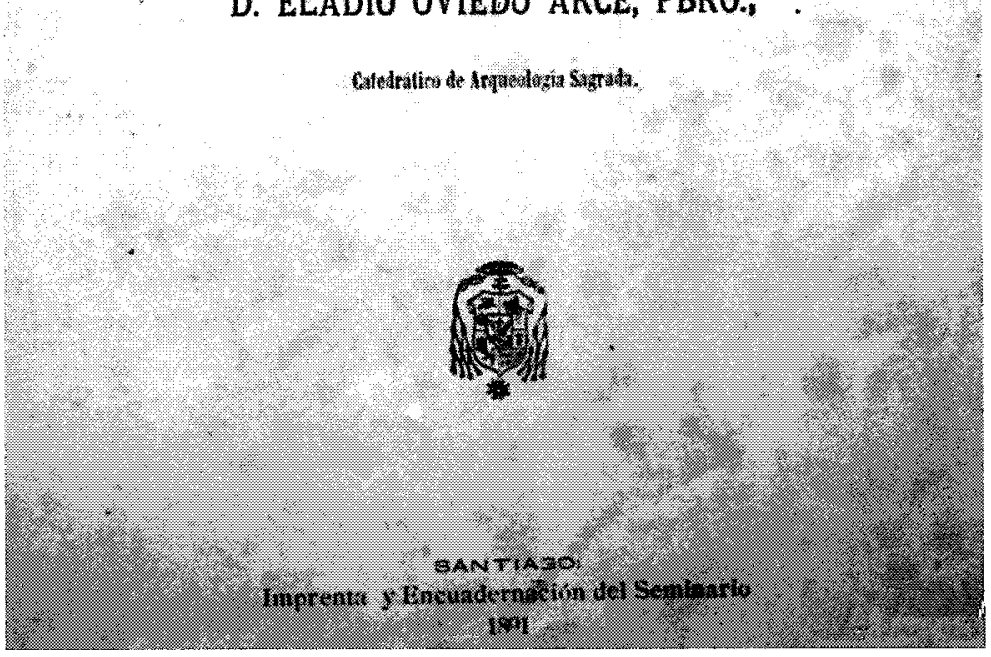

Además, el Boletín Oficial del Arzobispado de Santiago, así lo confirma, otorgando la custodia de las alhajas y obras de arte a los párrocos y prohibiendo su enajenación y venta: de haber habido un museo se habrían solicitado estos objetos para salvaguardarlos en él.

En numerosas circulares de la Nunciatura Apostólica a lo largo de los años, se previene de los constantes robos en las iglesias y se dan instrucciones precisas a los párrocos para garantizar la custodia de dichos objetos artísticos y documentos históricos.

Comprendemos que, ante la inexistencia de un Museo de la Diócesis donde depositar estos objetos, se produjeran numerosos robos y atentados contra estos bienes, muchos de ellos desaparecidos para siempre.

"CUAdERnOS DE ESTUdiOS GALlEGOS", Tomo XLIV, Fascículo 109, Santiago 1997. 


\section{LA SITUACIÓN DE LAS COLECCIONES Y MUSEOS ECLE- SIÁSTICOS GALLEGOS EN 1889: LA PROPUESTA DE JOSÉ VILLAAMIL Y CASTRO}

Por la publicación de una carta de Villaamil y Castro dirigida a Bernardo Barreiro en el diario La Voz de Galicia y en la revista Galicia Diplomática a finales del año 1889 , conocemos la situación a la que se había llegado en todo este proceso de reflexión sobre la constitución de museos de la Iglesia. El resultado tangible fue el proyecto de dos museos compostelanos de titularidad eclesiástica: el Museo del Colegio de Misioneros de Tierra Santa y Marruecos en el convento de San Francisco y el Museo de la Diócesis en el Seminario Central situado en el monasterio de San Martín Pinario.

Paralelamente se abría muy cerca de Galicia el Museo Arqueológico cristiano de Astorga, para lo cual, el Obispo había enviado una circular al clero de su Diócesis, participándoles los hechos y solicitando el envío de objetos con destino al museo. Era un ejemplo claro de los resultados efectivos del Congreso Católico del año anterior ${ }^{12}$.

Villaamil y Castro, que había intentado por todos los medios el establecimiento de un Museo Arqueológicọ en Santiago de carácter civil, - para lo cual depositó parte de su valiosa colección personal en la Sociedad Económica de Amigos del País, con la esperanza de que sirviera de acicate para la definitiva instalación del primer Museo público de Galicia - abrió otro frente de acción importante en el Congreso Católico lanzando la idea de constituir museos en todas las Diócesis.

En lo que respecta a Galicia, su propuesta fue muy osada: un sólo Museo Diocesano gallego en Compostela y no cinco como correspondería a las cinco Diócesis. En efecto, la viabilidad de establecer cinco museos diocesanos gallegos en lugar de uno era bastante incierta. Por este motivo, propuso un solo museo y en Santiago por ser «la gran metrópoli gallega en las dos elevadas esferas de la Religión y de la Ciencia» ${ }^{13}$.

\footnotetext{
$12 \ll$ La circular del obispo de Astorga participando a su clero la creación de un Museo Arqueológico Cristiano en el Seminario Conciliar», Galicia Diplomática, IV, Santiago, 1889, pp. 304-305.

13. «Museo Arqueológico. Carta de Villaamil y Castro a Bernardo Barreiro de V.V.», Galicia Diplomática, IV, Santiago, 1889, pp. 305-307.
}

"CUADERNOS DE ESTUDIOS GALLEGOS", Tomo XLIV, Fascículo 109, Santiago 1997. 
La realidad nos muestra que, efectivamente sólo se inició por aquel entonces un único proyecto de Museo diocesano en Galicia. Intuimos que uno de los problemas de peso quizás para que no se desarrollara el proyecto fue -y sigue siendo - la poca disposición de las Diócesis e incluso las parroquias, iglesias... para enviar objetos que formaban parte de su patrimonio para la constitución de este museo. Por otro lado, no parecía haber una persona entusiasta en desarrollar esta labor. Nos referimos en concreto al profesor titular de arqueología sagrada del Seminario Conciliar de Santiago, Antonio López Ferreiro. ¿No debería haber sido él la persona adecuada para desarrollar el proyecto? Nada sabemos al respecto, pero tras consultar la obra de este erudito no encontramos absolutamente ninguna referencia a su contemporáneo Museo del Seminario, que en teoría se había creado para ayudar a profesores como él en el desarrollo de la enseñanza práctica de la Arqueología Sagrada. Quizás para López Ferreiro fue prioritario el desarrollo de su gran obra sobre la historia de la Iglesia de Santiago, en la que estuvo trabajando largos años, y por la que dejó diversas ocupaciones, entre ellas la de la enseñanza de Arqueología Sagrada.

\section{MUSEOS Y COLECCIONES ECLESIÁSTICAS EN LAS GUÍAS Y MONOGRAFÍAS DE LA CIUDAD DE SANTIAGO: EL MUSEO DEL SEMINARIO CENTRAL O MUSEO DE SAN MARTÍN Y EL MUSEO FRANCISCANO}

Son muy confusas las denominaciones que se otorgan a las diferentes colecciones eclesiásticas en las guías y monografías de Santiago consultadas de finales del siglo XIX y principios del XX. Lo cierto es que, nos hacían dudar de si el origen de las colecciones de los conventos de San Martín o San Francisco, era la enseñanza de la Arqueología Sagrada o por el contrario, las enseñanzas científicas. En el primer caso, estaríamos sin duda ante el proyectado museo diocesano y en el segundo más bien ante un fenómeno de coleccionismo científico con una vertiente pedagógica importante: la enseñanza práctica de las ciencias físico-químico-naturales.

Si bien tenemos noticia de la existencia de colecciones, tanto en el Seminario Central de San Martín Pinario como en el convento de San Francisco de Santiago, tras nuestra investigación podemos decir que sin 
duda se refieren a colecciones de naturaleza científica integradas en gabinetes destinados a la enseñanza de los seminaristas y colegiales. Junto a estos objetos de flora, fauna y aparatos de física y química..., se encontraba alguna que otra colección de antigüedades de menor importancia.

Era usual en el siglo XIX que las antigüedades se presentaran junto a todo tipo de objetos curiosos y de la naturaleza al igual que en otros gabinetes de la época, antecedentes directos de nuestros museos. Así ocurría en el Gabinete de Historia Natural de la Universidad que, hasta no recibir en 1906 la denominación de Museo de Historia Natural, no separó las pequeñas colecciones de antigüedades y curiosidades de las más numerosas e importantes de fauna, flora y gea.

Al comenzar este estudio, teníamos indicios de la presencia de colecciones históricas en Santiago de carácter eclesiástico, constituídas a lo largo de la segunda mitad del siglo XIX: nos referimos concretamente a las colecciones del Seminario Central en el Monasterio de San Martín Pinario y a las del Colegio de Misiones para Tierra Santa y Marruecos en el Convento de San Francisco.

El principal problema fue determinar el origen y contenido de las mismas. En este estado de confusión de elementos, dudábamos acerca de las noticias que nos proporcionaban las guías y monografías de la ciudad, que nos situaban a finales del siglo XIX y principios del XX un Museo de San Martín Pinario, o un Museo franciscano o Misional...

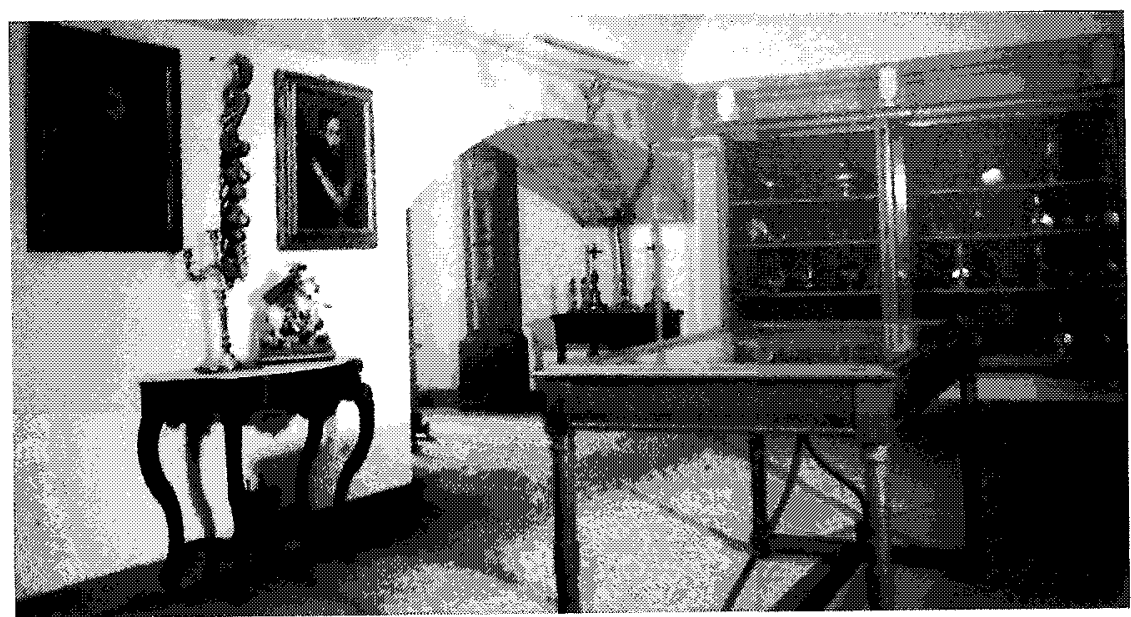

Montaje de la Colección actual del Seminario Mayor de Santiago.

"CUADERNOS DE ESTUDIOS GALLEGOS", Tomo XLIV, Fascículo 109, Santiago 1997. 


\section{Museos eclesiásticos de Santiago en Guías y Monografias}

1886 - B. Barreiro de Vázquez Varela, Guía artística, arqueológica y militar de la Antigua Capital de Galicia Santiago de Compostela.

- Museo franciscano.

1915 y 1920 - R. López y López, Santiago de Compostela. Guía del peregrino y del turista.

- Museo en San Martín.

1926 - R. Otero Pedrayo, Guía de Galicia

- Colecciones científicas de San Francisco.

1032 - J. Filgueira Valverde, Guía de Santiago de Compostela

- Museo de la Catedral.

1943 - R. López y López, Santiago de Compostela. Guía del peregrino y del turista.

- Museo de la Catedral

- Gabinetes de San Francisco

- Museo de San Martín Pinario

1989 - J. Carro Otero, Santiago de Compostela

- Museo de San Payo de Antealtares

- Museo de la Catedral

- Museo de la Colegiata de Sar

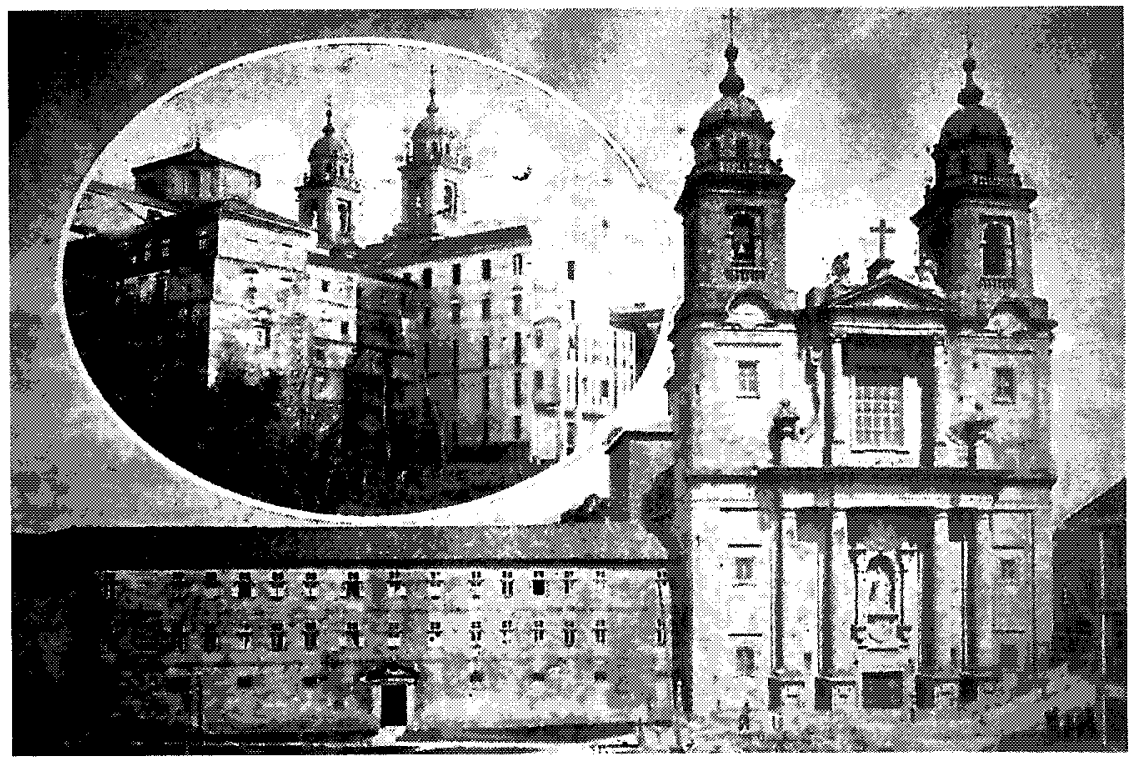

Santiago. Vistas parciales del Colegio de Misiones.

"CUADERNOS DE ESTUdIOS GALLEGOS", Tomo XLIV, Fascículo 109, Santiago 1997. 
Comenzaremos con el primero de ellos. En primer lugar, debíamos despejar la duda de si realmente lo que se denominó Museo de San Martín Pinario en tres de las ediciones de la obra de Román López y López, Santiago de Compostela. Guía del peregrino y del turista-ediciones de 1915,1920 y 1943 - se refería al proyectado museo diocesano o a las colecciones científicas de los gabinetes de historia natural, física y química, asignaturas que se impartían a los futuros sacerdotes en el Seminario:

«Monasterio de San Martín Pinario:

Dos notables claustros forman parte del edificio. Además de las aulas, bibliotecas, museo, y de la capilla, donde se guarda el sistema óseo del Arzobispo Sanclemente recubierto de cera y el corazón del fundador el Arzobispo Vélez, es digna de mención la escalera al aire, colmo del atrevimiento de un arquitecto» ${ }^{14}$.

Ante la ausencia de documentación del Seminario Conciliar referida a colecciones, gabinetes o museos, el estudio comparativo de las guías de la ciudad de estas mismas fechas, nos llevó a concluir, que dicho museo de San Martín que cita López y López, no es el proyectado Museo Diocesano sino, como indica Otero Pedrayo en 1926, una colección a la que denomina museo de historia natural. Salvo estos dos autores, ninguno más vuelve a mencionar colecciones o museos en San Martín.

Una vez despejada esta duda, buscamos referencias concretas de estas dos instituciones de enseñanza como eran, el Seminario Central y el Colegio de Misiones.

Respecto al Seminario Central, a través de la obra de Fernández Sánchez-Freire Barreiro de 1880, sabemos que era un centro dotado de todos los medios de enseñanza similar a aquellos «con que el Estado enriquece diariamente a los que están bajo su dependencia y dirección»; el Padre Jerónimo Rojas de la Compañía de Jesús hizo un viaje a París durante la última Exposición Universal, «donde adquirió muchas y preciosas colecciones y aparatos no sólo para este Gabinete sino también para el de Física y para el laboratorio de Química».

${ }^{14}$ R. López y López, Santiago de Compostela. Guía del peregrino y del turista, Tip. El Eco Franciscano, Santiago, 1915, pp. 102-103.

"CuAdernOS DE ESTUdios GALLEGOS", Tomo XLIV, Fascículo 109, Santiago 1997. 
Era pues un Gabinete bien dotado de material y que había adquirido parte de sus fondos en el extranjero, al igual que su coetáneo el Gabinete de Historia Natural de la Universidad.

La asignatura de Física experimental apareció por primera vez en el curso $1856-57$ y la de Historia natural en el de 1868. Los gabinetes del Seminario fueron muy importantes, al menos hasta el año 1927 en que Couselo Bouzas apuntaba «lo que podemos decir es, que entonces como ahora para el estudio de la Física e Historia Natural con provecho se necesitan gabinetes... Éstos no existieron hasta después del año 1875, en el tiempo del Cardenal Payá y Rico, tantas veces mencionado» ${ }^{15}$.

La descripción del Gabinete de Historia Natural que comunicaba con la cátedra, es la siguiente:

«...las paredes están cubiertas con las planchas murales de Achilles Conte. Sería impertinente dar aquí la lista de las numerosas y ricas colecciones que contiene, perfectamente clasificadas y dispuestas en magníficos armarios; pero debemos hacer especial mención de los

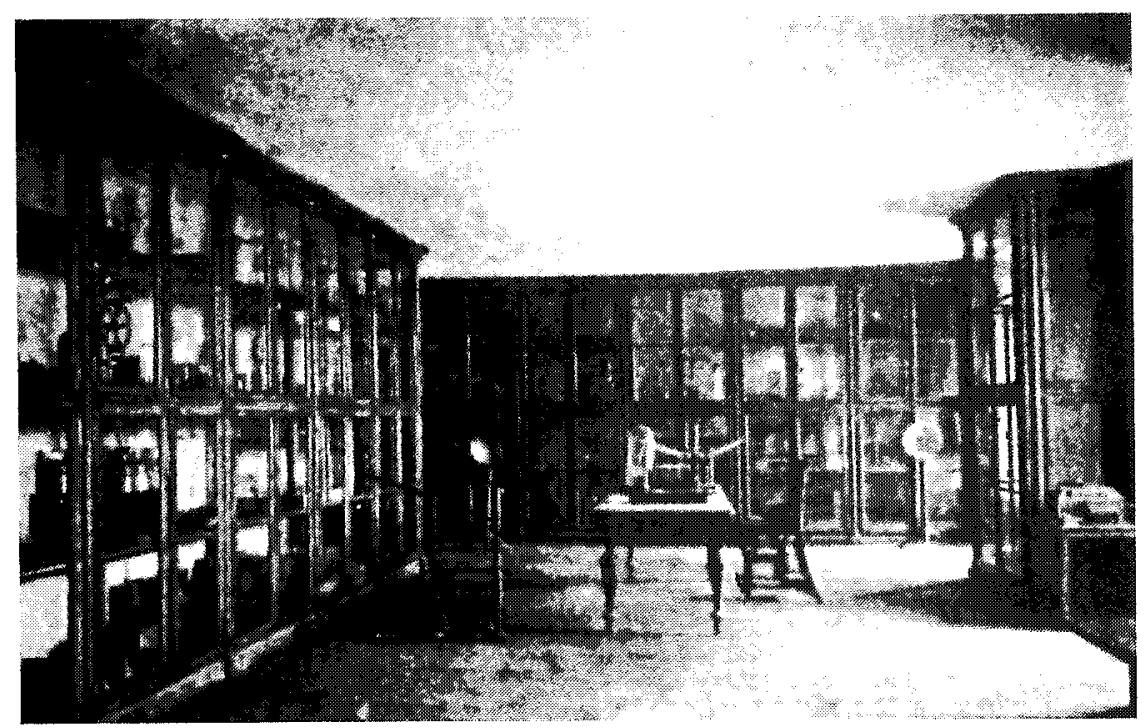

Gabinete de Física y Química del Seminario Central en el siglo XIX.

15 J. Couselo Bouzas, Fray Rafael de Vélez y el Seminario de Santiago, Tip. del Seminario CENTRAL, 1927, p. 95.

"CUADERNOS DE eSTUdIOS GALLEGOS", Tomo XLIV, Fascículo 109, Santiago 1997. 
ejemplares siguientes:

- Una serpiente de cascabel.

- Una límula.

- Varias ardillas.

- La lira.

- El árgos.

- El águila real.

- El apteris.

- El lophophorus impejamus.

- Algunos faisanes.

- Cuatro aves del paraíso.

- Pájaros-moscas, que forman una de las más ricas colecciones de los museos de España.

- Esqueletos muy bien preparados.

- Una figura clástica en que se ve admirablemente preparado el organismo.

- Una colección de insectos, que contiene algunos de los alrededores de Santiago y muchos y preciosísimos exóticos de todas partes del mundo.

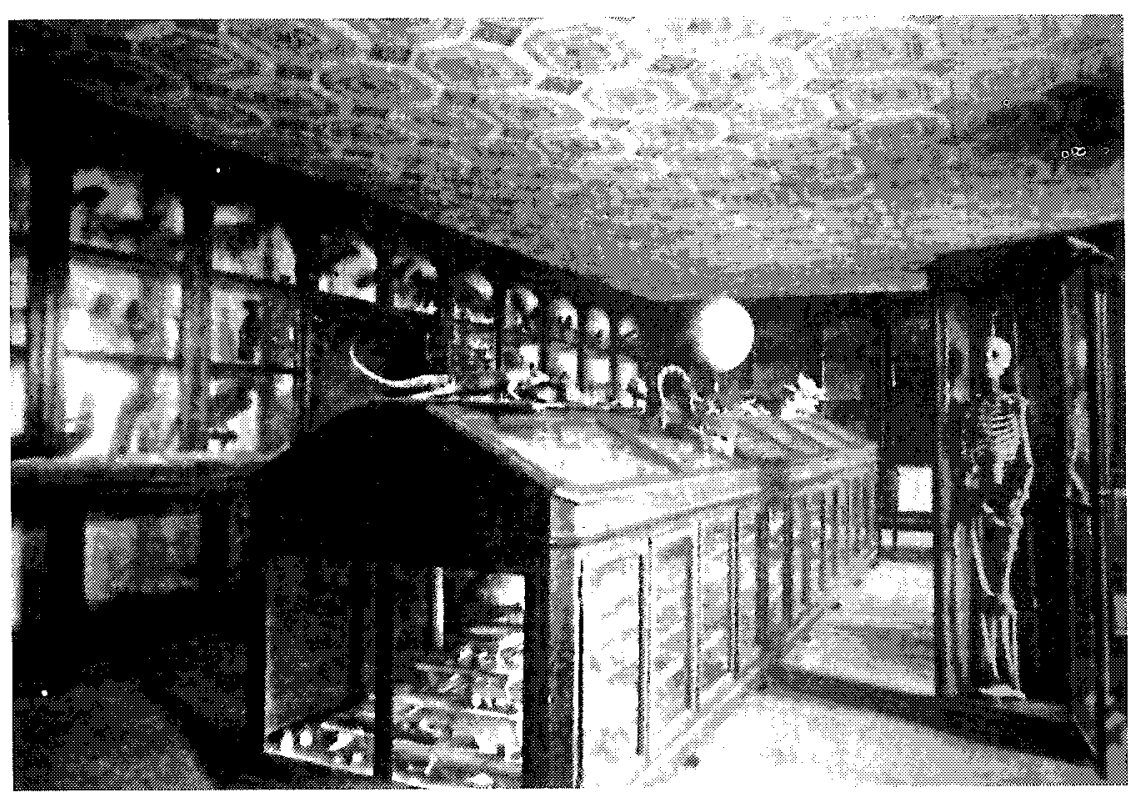

Gabinete de Historia Natural del Seminario Central.

"CUADERNOS DE ESTUdiOS GALLEGOS", Tomo XLIV, Fascículo 109, Santiago 1997. 
- Otra bastante numerosa y regular de conchas.

- Un centenar de rocas.

- Otro centenar de figuras de cristalización.

- Finalmente muchos ejemplares de minerales y de fósiles, entre estos últimos el trilobites ammonites y una pata de ictiosaurio.»

En 1927 Couselo Bouzas apuntaba respecto al Gabinete de Historia Natural: «no es un gabinete muy completo, pero es lo suficiente para un estudio elemental de esa asignatura...».

En el Gabinete de Física se mencionan también unos pocos aparatos: un péndulo, un regulador eléctrico, un microscopio solar, un fuelle acústico, y la sirena ${ }^{16}$. Citamos todas estas referencias porque algunas de estas colecciones han llegado hasta nuestros días: parte de las de historia natural y de física y además, otras que no se mencionan en dicha obra como el botamen de la antigua botica del Monasterio benedictino de San Martín Pinario. La antigua botica se encontraba situada en la planta baja del Monasterio junto a los laboratorios y almacenes entre otros, mientras que los gabinetes se situaban en la planta primera.

Otro tanto parece ocurrir con las colecciones de San Francisco. A este respecto, la primera mención de museo que encontramos en la Guía histórica, Artística, Arqueológica y militar de la Antigua Capital de Galicia Santiago de Compostela de Bernardo Barreiro de V.V. de 1886, es la de museo de antigüedades en el convento de San Francisco.

Este dato, no aparecería en la obra de Fernández Sánchez-Freire Barreiro, Santiago, Jerusalén y Roma, de 1880: únicamente se citaban en San Francisco «...salones muy capaces para los actos de la Comunidad y para los académicos, cátedras y gabinetes, reducidos hoy a lo estrictamente necesario para la enseñanza de las ciencias físico-matemáticas y naturales».

Sin embargo en la Guía de Santiago y sus alrededores, de 1885, estos autores nos dan una descripción de los que fueron las colecciones, no encontrando ningún indicio de museo propiamente dicho:

${ }^{16}$ Fernández Sánchez-Freire Barreiro, Santiago, Jerusalén y Roma, Santiago, 1882, pp. 284-285.

"CUADERnOS DE ESTUdios GALlEGOS", Tomo XLIV, Fascículo 109, Santiago 1997. 


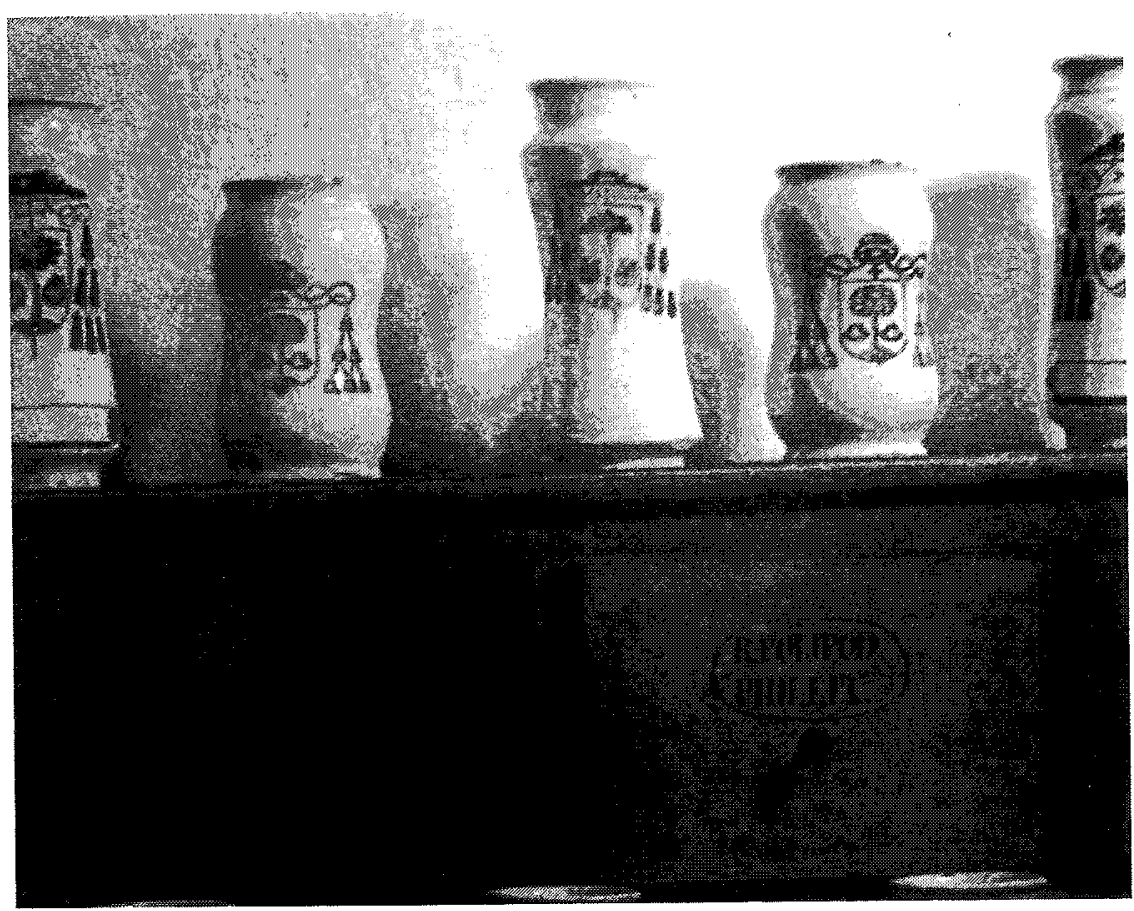

Antiguo Botamen de la Botica vieja de San Martín Pinario.

«Hay salones muy capaces para los actos de la comunidad y para los académicos, cátedras y Gabinetes, que reducidos desde hace cinco años a lo estrictamente necesario para la enseñanza de las ciencias físico-matemáticas y naturales, a las cuales, lo mismo que a la teología, filosofía, lenguas, historia y literatura, concédese aquí preferente atención... Pasan de doscientos los aparatos de física... El laboratorio de química tiene más de noventa aparatos...

También el Gabinete de historia natural contiene ejemplares interesantes de mamíferos, aves, reptiles y peces.

Los insectos llenan ciento treinta y seis cajas y setenta y seis frascos; la colección de conchas pasa de setecientos ejemplares, y la de fósiles de mil seiscientos; el herbario, en fin, que está muy bien conservado forma nueve volúmenes.

La sección de mineralogía es igualmente rica: pasan de tres mil tres-

"CUADERNOS DE ESTUdios GALLEGOS", Tomo XLIV, Fascículo 109, Santiago 1997. 


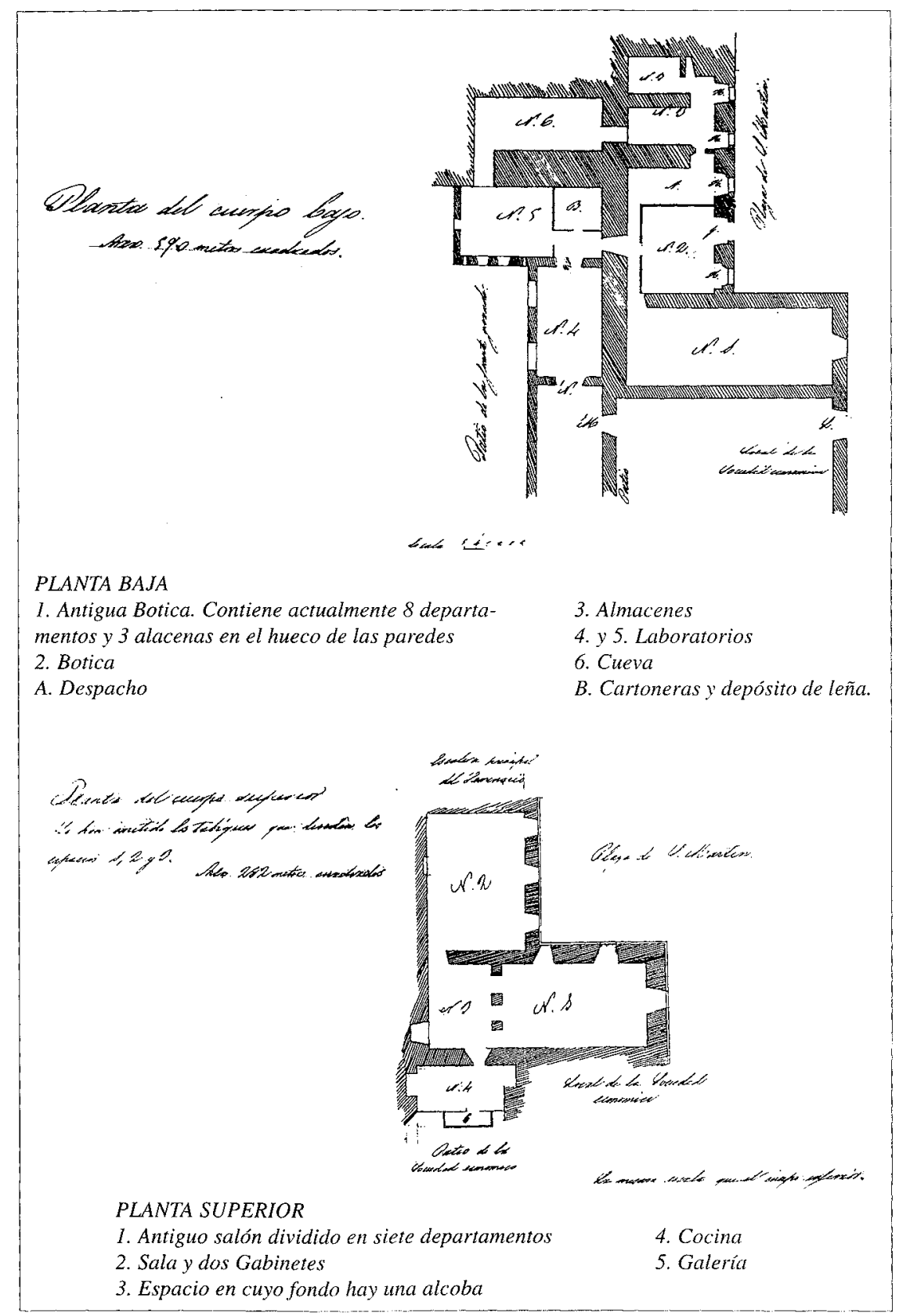

Archivo Histórico Diocesano de Santiago, Locales del S. Santiago, Botica comprada. $A^{a}$. 1883, Serie Seminario Conciliar, Mazo $2^{\circ}$.

"CUADERNOS DE ESTUdIOS GALLEGOS", Tomo XLIV, Fascículo 109, Santiago 1997. 
cientos los objetos que encierra, entre los cuales hay preciosas ágatas, cristales de roca, etc., etc. Posee asimismo este gabinete una colección completa en madera de modelos de cristalización de todas clases y sesenta y cinco mapas iluminados, que facilitan el estudio de la zoología, botánica y mineralogía. No debemos pasar en silencio una colección de antigüedades colocadas en tres cajas ${ }^{17}$.

Sin duda que Bernardo Barreiro se dejó llevar por el deseo de ver realizado su sueño de instituir museos en Santiago. Ya anunciaba en su revista, Galicia Diplomática el hecho de que pronto se abrirían dos museos eclesiásticos: el de San Martín y el de San Francisco, y no es de extrañar que denominara anticipadamente a las colecciones de San Francisco museo de antigüedades aunque estas se redujeran por aquel entonces, 1886 , «a tres cajas».

Otero Pedrayo en su guía de 1926, cita de nuevo las colecciones científicas de San Francisco. Está claro, que en la primera mitad del siglo $\mathrm{XX}$, al menos en Santiago, existe una confusión conceptual respecto a lo que eran simples colecciones y lo que hubieran podido ser museos.

No obstante, hoy día es común aún denominar Museo a simples Colecciones. Lo curioso del caso es, que cuando estas colecciones o museos se citan en las guías es porque eran visitables. No es que estuvieran abiertas al público permanentemente sino, que se abrían cuando el público acudía a estos centros y solicitaba permiso para contemplarlas.

\section{LÓPEZ Y LÓPEZ (1943)}

El Museo Misional de San Francisco:

«se compone de una curiosa colección de objetos raros, flora y fauna, maquetas, etcétera de los Lugares Santos. (Dirigirse a la Portería del Convento)». p. 157.

De las colecciones de San Francisco tenemos una referencia más precisa a través del número especial de 1912 de la revista El Eco franciscano publicado con motivo del cincuentenario de la fundación del Colegio de

${ }^{17}$ Fernández Sánchez-Freire Barreiro, Guía de Santiago y sus alrededores, Santiago, 1885 , pp. 308-309.

"CUADERNOS DE ESTUDIOS GALLEGOS", Tomo XLIV, Fascículo 109, Santiago 1997. 
Misiones para Tierra Santa y Marruecos 1862-191218. Vamos a agrupar las colecciones en dos grupos: por un lado, las pertenecientes a los gabinetes de Física, Química e Historia Natural y por otro, las consideradas como colecciones de las que podía decirse que casi era un museo.

\section{Los Gabinetes Cientificos de San Francisco}

El padre Marquina mandó construir la Biblioteca y también habilitó un local para los gabinetes de Física e Historia Natural para los cuales adquirió instrumentos, aparatos y demás objetos necesarios para el provechoso estudio de las ciencias.

El local era un rectángulo que se extendía de E. a O. y tenía «más de 17 metros de largo y 7,40 de ancho, con luces a los tres lados». Disponía de estantes con puertas de cristal en todos los lienzos, algunos de los cuales alcanzan la altura del techo.

A continuación transcribimos la descripción íntegra, ya que es la única referencia que tenemos de las colecciones y gabinetes, hoy desaparecidos casi por completo:

«El gabinete de Física es de los más completos en su clase: sin hacer mención de la parte de Química, contiene más de trescientos instrumentos, los cuales están colocados en el mayor de los estantes, que es doble, comenzando por el más próximo a la entrada...

Los aparatos que no hallaron cabida en dicho estante, se encuentran en los de los lados, y son pocos. De todos los instrumentos no mencionaremos sino algunos: en Mecánica, dos balanzas de precisión... En la Hidrostática, la trompa de Geisler para hacer con la perfección que cabe el vacío: hay también la máquina neumática de mercurio de Sprengel y una horizontal metálica de doble efecto poco conocida.

En Fonología, el fonógrafo y gramófono; en Termología el aparato de Cailletet para la liquidación de gases, el tren y el vapor: en Fotología un buen microscopio solar y un precioso modelo de microscopio de luz ordinaria de la Casa Reichert de Viena: llega a tres mil diámetros de aumento lineal, le acompañan varios accesorios: hay también cinematógrafo y una pequeñísima partícula de Radium: en Electrología cinética un Carrete

${ }^{18}$ El Eco Franciscano, «Filial homenaje al Colegio de Misiones para Tierra Santa y Marruecos en el Quincuagésimo año de su instalación en Santiago de Compostela, 1862 1912», Año XXIX, núm. 439, Santiago, 1912.

"CUADERNOS DE ESTUDIOS GALlegOS", Tomo XLIV, Fascículo 109, Santiago 1997 
Ruhunkorff de 25 centímetros de chispa, un Ohmetro que puede medir hasta 20 Megomhs, un Resonador Oudin, Tubo de Crookes para los rayos catódicos, tubos de Geisler, y tubos para los rayos X, tren eléctrico, Giróscopo electro magnético, aparatos para las ondas hertzianas, y la Telegrafía sin hilos, sistema ruso-francés-Poppoff-Ducretet. Hay además un transformador o enderezador de corriente electrolítico, Tipo Faria para 20 amperes.

En la parte de Química aún hay bastantes aparatos y cuerpos para verificar experiencias. La mayor parte de los instrumentos, y de los más antiguos, se trajeron de Inglaterra, bajo el gobierno del P. Juan Marquina; los más modernos, casi todos de París. En 1903, siendo Provincial el P. José Catalá, el Venerable Definitorio destinó 3.000 francos a este objeto, y poco después siendo Superior el mismo, una persona bienhechora dió expresamente para la Física 7.000 francos, pidiendo se ocultar su nombre.

El gabinete de Historia Natural es a su vez importante. Hay un mapa anatómico de Medicina para el estudio de la Fisiología, y el esqueleto en piezas sin unir, unas ochenta cajas de insectos, una colección variadísima de conchas; muchos paquetes de herbarios, más de quinientas vistas para proyección de Zoología y Botánica, tres colecciones de minerales, una de 516 ejemplares traída de Inglaterra, otra de 526 y la última de rocas.

Hay buenos ejemplares de fósiles en moluscos, madera y molares de Elefans primigenius y Mastodonte, incrustaciones de helechos y varios hongos».

Las colecciones de objetos antiguos o curiosos o pequeño «museo» del convento de San Francisco

Compartiendo local con las colecciones de los tres gabinetes anteriormente citados, se encontraba, en el testero de la sala lo que «puede decirse es un museo por las diversas cosas que contiene».

El contenido de este pequeño museo era muy variado: todo tipo de objetos curiosos o antiguos, monedas, una momia de un gato traída de Egipto, objetos de etnografía... En el monográfico de El Eco Franciscano de 1912, se citan algunas de ellas:

«Un pergamino que contiene el Pentateuco en hebreo enviado por el P. Aquilino Llaneza, Procurador General de Tierra Santa e hijo del Colegio, una momia de un gato traída de Egipto por el P. Samuel Eiján,

"CUADERNOS DE ESTUdIOS GALLEGOS", Tomo XLIV, Fascículo 109, Santiago 1997. 


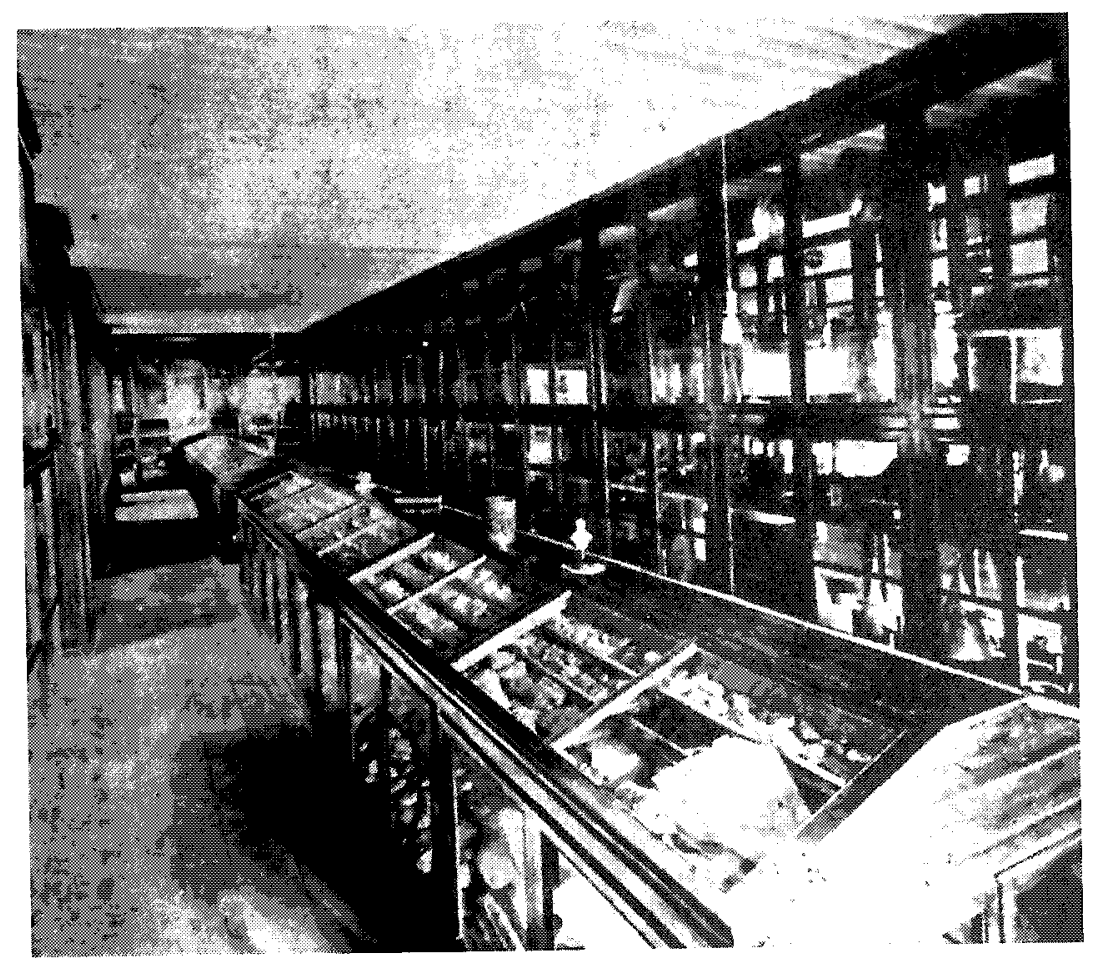

Colegio de Misiones. Gabinete de Física e Historia Natural.

y que da idea de cómo allí embalsamaban los cadáveres, pues lo mismo hacían con las personas; varios ídolos de China, Egipto, Siria y América, adornos que usan los indios de América y varias vasijas de tomar el mate, un cerrojo que fue de la puerta exterior del Santo Sepulcro, unas cuantas raíces de mandrágoras, y otra multitud de objetos antiguos y curiosos. Hay asímismo una buena colección de monedas distribuídas en 40 tablas en las que se han hecho cavidades a propósito para contenerlas. Treinta y cuatro tablas están clasificadas por naciones, habiendo muchas de la antigua Roma y de la España romana».

En 1943, López y López cita en su guía de Santiago el Museo Misional: se compone de una curiosa colección de objetos raros, flora y fauna, maquetas etcétera de los Lugares Santos. «Dirigirse a la portería del convento». 


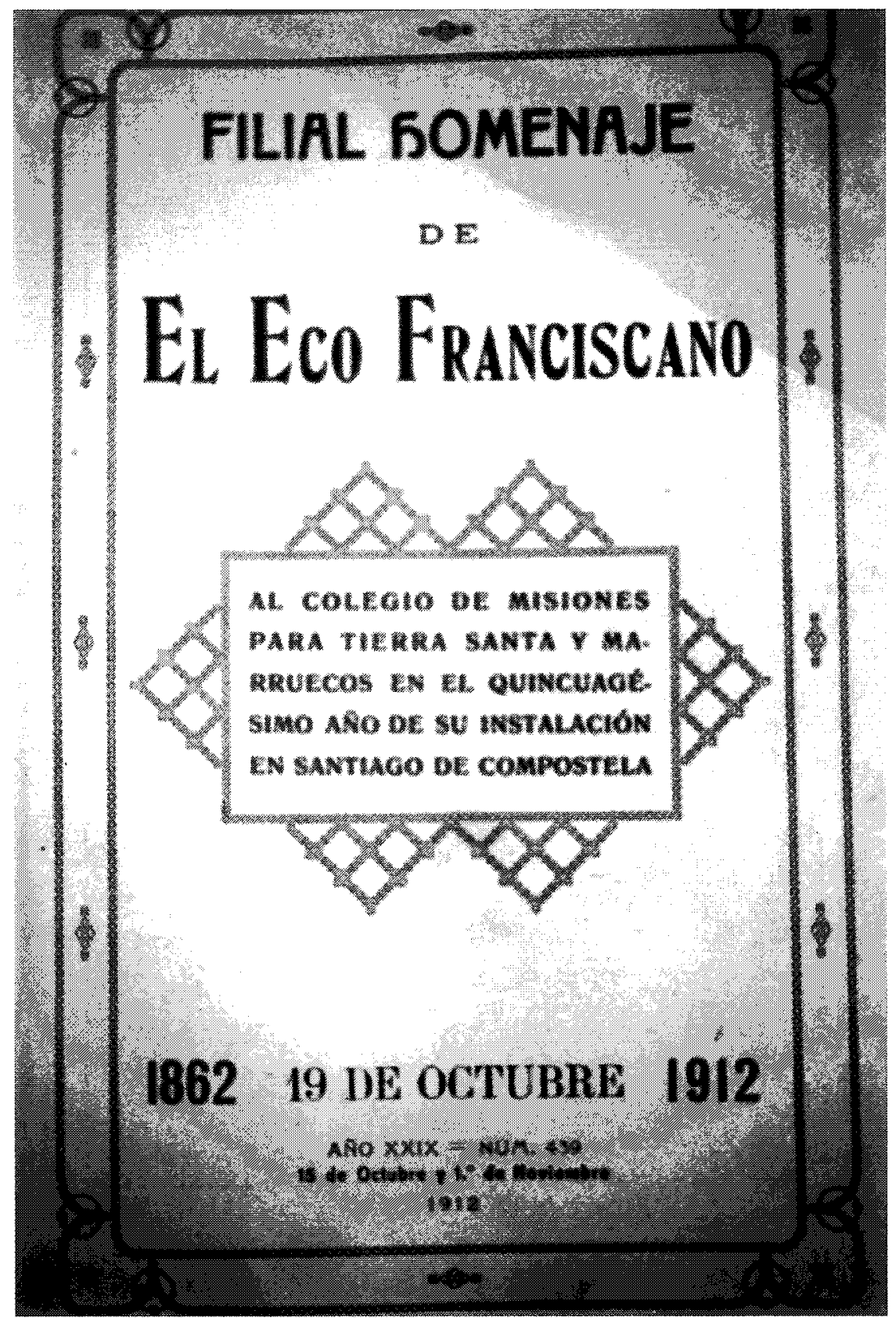


Muchas de estas colecciones desaparecieron, otras se encuentran en cajas en diversas dependencias del convento de San Francisco y algunas, probablemente pasaron a formar parte del Museo de Terra Santa en el mismo convento de San Francisco, junto a los fondos depositados procedentes de la gran e impresionante exposición celebrada en el año 1954 en Madrid sobre Tierra Santa.

Este último Museo fue inaugurado en 1993 en el convento de San Francisco y forma parte ya de otra historia más reciente. Por último añadir que, además de estas colecciones y del Museo de Terra Santa, cuenta el convento de San Francisco en la actualidad con una colección notable de objetos de plata.

\section{EL ACTUAL MUSEO DIOCESANO DE SANTIAGO DE COMPOSTELA}

Algo más de un siglo después de las últimas noticias respecto al proyecto de realización de un Museo diocesano en Santiago de Compostela, y después de haber hecho repaso a lo que podemos denominar colecciones históricas eclesiásticas de Santiago desaparecidas, retomaremos la idea de un museo de este tipo.

No sin antes precisar, que existe otro museo eclesiástico fundamental para la historia de la museología en Santiago: nos referimos al Museo de la Catedral. Por la complejidad que presenta y por ser un museo no desaparecido, no ha sido incluido en este estudio, pero hemos de considerarlo como el más importante de los museos históricos de Santiago y que continúa abierto al público en la actualidad.

Hecha esta precisión veamos la situación actual. En el Seminario de San Martín, en el presente existen varias dependencias que albergan diversas colecciones, entre las que se encuentran objetos de plata, planchas de grabados y material de la antigua imprenta del Seminario, el botamen de farmacia del antiguo Monasterio, algunas esculturas y un gran óleo de Claudio Coello, entre otros.

Estas dependencias fueron acondicionadas en los años ochenta por estudiantes y profesores del Seminario, presentándose actualmente como una pequeña colección privada no abierta al público. Parte del antiguo gabinete de historia natural se encuentra en almacén en el Seminario 
Mayor, mientras que otra se trasladó hace unos años al Seminario Menor donde hoy se puede contemplar expuesta en vitrinas. Dispone de una sala amplia y en ella se encuentran colecciones mineralógicas y zoológicas al servicio de la enseñanza de las ciencias naturales del Seminario.

Además de estas colecciones, en los años noventa se inició un gran proyecto: la constitución en Santiago de un Museo Diocesano.

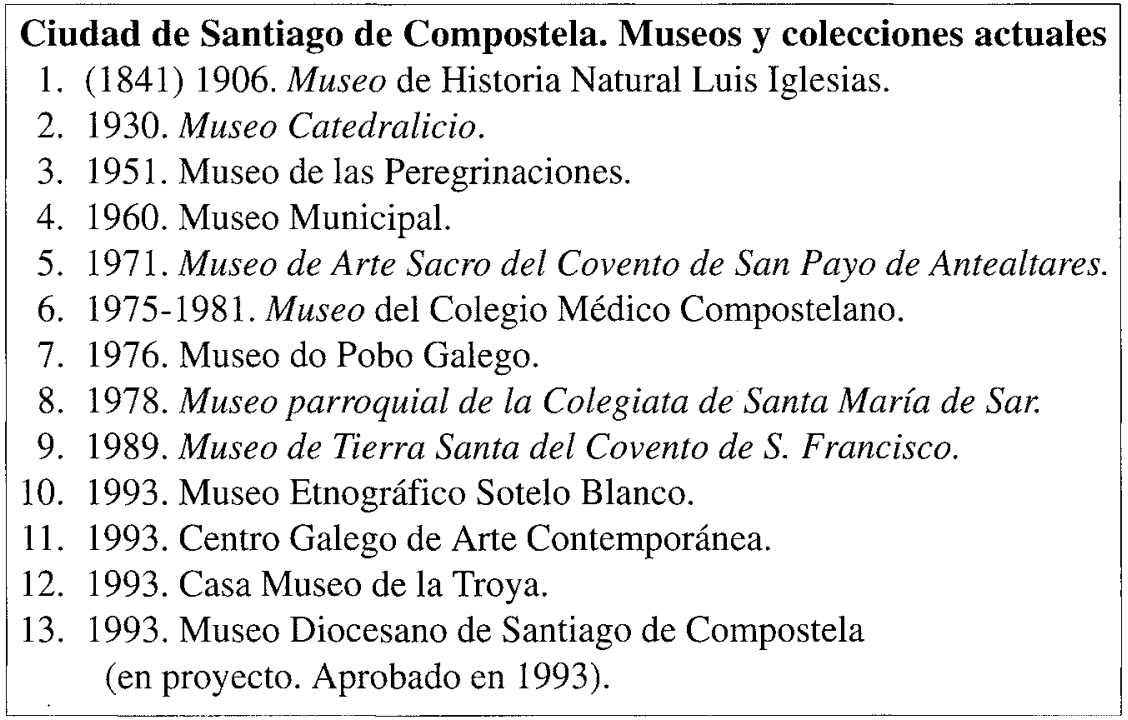

El Museo Diocesano de Santiago de Compostela fue creado por decreto del Arzobispado de Santiago de Compostela el 1 de octubre de 1993 en la sede del Monasterio de San Martín Pinario y autorizada su constitución por la Subdirección Xeral do Patrimonio Histórico e Documental el 22 de noviembre del mismo año.

El lugar que se prevee ocupe este museo, aún en fase de proyecto, son los cuatro niveles rehabilitados por la Consellería de Cultura en el Monasterio, sede de importantes exposiciones inauguradas por la de Galicia no Tempo. Su titularidad es eclesiástica por tanto, así como los fondos que pretende albergar. Sería un museo que se financiaría con presupuestos diocesanos.

Los fondos con los que ya cuenta este futuro museo, son los que componen actualmente el Tesoro de la Iglesia de San Martín Pinario, el botamen de farmacia del monasterio benedictino y las antiguas colecciones de Historia Natural, Física... del Seminario. No obstante, se tendría en 
cuenta para su formación la totalidad del patrimonio mueble de la Diócesis. En octubre de 1993, se contaba con un inventario de alrededor 3.000 fichas de Patrimonio Mueble de la Diócesis además de las elaboradas por el Ministerio de Cultura y el Museo de Pontevedra.

Existe la propuesta de que este Museo de la Archidiócesis pueda funcionar como Cabecera de la red de Museos Eclesiásticos de Galicia. Esto significaría que, a través de esta cabecera se articularía una estructura económica, administrativa y técnica permanente fruto de los acuerdos Xunta-Iglesia de Galicia. Este reconocimiento sería importante pues, llevaría aparejado los efectos técnicos y recursos económicos suficientes en cuanto a protección y apoyo que le prestaría la Xunta de Galicia.

Del museo diocesano de Santiago de Compostela poco más podemos decir. De momento, estos son los únicos datos oficiales con los que contamos.

Esperamos, que en un plazo no muy largo, se puede realizar este gran proyecto. Teniendo en cuenta que es el segundo intento de museo diocesano en la ciudad de Santiago, esperamos se pongan los medios necesarios para su realización en un futuro próximo.

\section{BIBLIOGRAFÍA}

ACOSTA DE LA TORRE, L.: Memoria sobre el estilo más conveniente para los edificios religiosos, sobre Museos Diocesanos y sobre Juntas Periciales Consultivas respecto a Arquitectura, Antigüedades y Bellas Artes Sagradas, Tip. de los Huérfanos, Madrid, 1889.

BARREIRO DE V.V., B.: Guía Histórica, Artística, Arqueológica y militar de la Antigua Capital de Galicia Santiago de Compostela, Imp. de José M. Paredes, Santiago, 1886.

«BARREIRO DE VÁZQUEZ VARELA, BERNARDO»: Gran Enciclopedia Gallega, III, p. 106.

«Bibliografía»: Galicia Diplomática, IV, Santiago, 1889, p. 254.

Boletín Oficial de la Diócesis de Santiago de Galicia: Imp. del Seminario Conciliar Central, Santiago de Compostela.

"CUADERNOS DE ESTUDIOS GALLEGOS", Tomo XLIV, Fascículo 109, Santiago 1997. 
BRAVO RODRÍGUEZ, E.L.: Guía documentada de Santiago de Compostela, o sea su historia y descripción de la ciudad y sus monumentos, Tip. Barrientos, Vigo, 1920.

CARRO OTERO, J.: Santiago de Compostela, Everest, León, 1989.

COUSELo BOUZAS, J.: Fray Rafael de Vélez y el Seminario de Santiago, Tip. del Seminario Central, Santiago, 1927.

DE SA BRAVO, H.: El Monasterio de San Martín Pinario, León, Everest, 1988.

DE SILVA POSADA, V.: «Las cátedras de Arqueología en los Seminarios», Galicia Diplomática, IV, Santiago, 1889, p. 83.

«El Congreso Católico reunido en Madrid», Galicia Diplomática, IV, 17, Santiago, 1889, pp. 139-140.

FERNÁNDEZ CASANOVA, C.: «La Sociedad Económica de Amigos del País de Santiago en el siglo XIX», Cuadernos del Seminario de Sargadelos n ${ }^{\circ} 36$, Edicións do Castro, Sada, 1981.

FERNÁNDEZ SÁNCHEZ-FREIRE BARREIRO: Guía de Santiago y sus alrededores, Santiago, 1885.

FERNÁNDEZ SÁNCHEZ-FREIRE BARREIRO: Santiago, Jerusalén y Roma, Santiago, 1880-2.

FERNÁNDEZ SÁNCHEZ-FREIRE BARREIRO: Santiago, Jerusalén y Roma, Santiago, 1880.

FERRANDO Y ARNAU, F.: Apuntes Históricos relativos al Colegio de PP. Misioneros Franciscanos de Santiago desde 1856 a 1896, El Eco Franciscano, Santiago, 1916.

FILGUEIRA VALVERDE, J.: Guía de Santiago de Compostela, Patronato Nal. del Turismo, $1^{\circ}$ edic., Madrid, 1932.

"CUADERNOS DE ESTUdIOS GALleGOS", Tomo XLIV, Fascículo 109, Santiago 1997. 
Galicia Diplomática, Vol. I-V, 1882-1893.

GARCÍA CORTÉS, C.: «Documentación colectiva del episcopado gallego en el siglo XX», Estudios Mindonienses, 3 y 4, 1987 y 1988, pp. 211-263, 507-555.

GARCÍA CORTÉS, C.: «El profesorado del Seminario Conciliar de Santiago y su labor científico-docente en la etapa universitaria (18761932)», Compostellanum, 1982, pp. 217-284.

GARCÍA CORTÉS, C:: «El Seminario Conciliar de Santiago. Nuevos datos para su historia», Compostellanum, 26, 1981, pp. 197-265.

LÓPEZ Y LÓPEZ, R.: Santiago de Compostela. Guía del peregrino y del turista, Tip. El Eco Franciscano, Santiago, $2^{\circ}$ edic., 1915; $3^{\circ}$ edic., $1920 ; 4^{\circ}$ edic. $1928 ; 6^{\circ}$ edic. $1943 ; 8^{\circ}$ edic. 1950.

«Los Museos de antiguiedades en Santiago», Galicia Diplomática, II, núm. 22, Santiago, 1883, pp. 165-166.

«Los Museos de la Diócesis», Galicia Diplomática, II, 30, Santiago, 1884, pp. 247-248.

«Los Museos de la Diócesis. La circular del obispo de Astorga participando a su clero la creación de un Museo Arqueológico Cristiano en el Seminario Conciliar», Galicia Diplomática, IV, Santiago, 1889, pp. 304-305.

«Muscelánea», Galicia Diplomática, II, 21, Santiago, 1883, p. 164.

«Miscelánea. Congreso Católico», Galicia Diplomática, IV, Santiago, 1889, p. 144.

NAVAL, F.: Elementos de Arqueología y Bellas Artes para uso de Universidades y Seminarios, Imp. y Enc. de José Saenz, Santo Domingo de la Calzada, 1904.

"CUADERNOS DE ESTUdios GALLEGOS", Tomo XLIV, Fáscículo 109, Santiago 1997. 
OTERO PEDRAYO, R.: Guía de Galicia, $1^{\circ}$ edic., Espasa Calpe, Madrid, 1926.

OVIEDO ARCE, E.: Seminario Conciliar Central Compostelano. Discurso inaugural del Curso Académico de 1891 a 1892, Imp. y Enc. del Seminario, 1891.

«Programa de los puntos sometidos al estudio del Congreso Católico y de las tesis para los trabajos», Bol. Oficial de la Diócesis de Santiago de Galicia, XXVIII, Imp. del Seminario Conciliar Central, Santiago, 1889, p. 42.

QUINTELA NAYA, C.: Guía de Santiago, Tip. Galaica, Santiago, 1903.

SISTO EDREIRA, R.: «A antiga botica do Mosteiro de San Martiño Pinario (Santiago). Catalogación das súas pezas», Ingenium, 4, publicacións do Seminario de Estudios Galegos, Edic. do Castro, 1994, pp. 125-139.

VILLAAMIL Y CASTRO, J.: «Museo Arqueológico. Carta de Villaamil y Castro a Bernardo Barreiro de V.V.», Galicia Diplomática, IV, Santiago, 1889 , pp. 305-307.

«Villaamil y Castro, José», Gran Enciclopedia Gallega, XXX, p. 122123. 